\title{
A STUDY ON THE BIOACTIVE POTENTIAL OF FRESH AND DRIED SPROUTS OF COCOS NUCIFERA L.-AN IN VITRO AND IN-SILICO APPROACH
}

\author{
ABIRAAMI VALLI S. , S. UMA GOWRIE** \\ Department of Plant Biology and Plant Biotechnology, Ethiraj College for Women, Chennai 600008, Tamil Nadu, India \\ Email: umasezhian@gmail.com
}

Received: 03 Nov 2016 Revised and Accepted: 17 Jan 2017

\begin{abstract}
Objective: The main objective of the study is to analyze the medicinal properties, by giving scientific validation to the existing bioactive compounds present in the coconut sprouts and recommending the coconut sprouts as a natural product for the treatment of bacterial infection leading to inflammations.
\end{abstract}

Methods: Phytochemical screening by qualitative and quantitative analysis of the primary and secondary constituents were carried out in aqueous and methanol extracts of the coconut sprouts (fresh and dried) using standard procedures. The phytochemicals were characterized using FT-IR, TLC and GC-MS analysis. Antibacterial activity was studied against several human pathogens by agar well diffusion method. Antioxidant activity using Reducing power, Hydrogen peroxide scavenging and DPPH radical scavenging methods and Anti-inflammatory activity through protein denaturation method were carried out. Further confirmation of the functional role of the phytoconstituent through in-silico docking was studied.

Results: The qualitative phytochemical screening revealed the presence of essential phytoconstituents. The quantitative analysis revealed the presence of maximum Carbohydrates $(0.60 \pm 0.1 \mathrm{mg} / \mathrm{g})$, Proteins $(39 \pm 0.8 \mathrm{mg} / \mathrm{ml})$, Flavonoids $(0.28 \pm 0.1 \mathrm{mg}$ QE/g) and Terpenoids $(95 \pm 1.2 \mathrm{mg} / \mathrm{g})$ in methanolic fresh coconut sprout extract with respective standards. Maximum zone of inhibitions were shown by Shigella flexneri, Salmonella typhi and Klebsiella pneumoniae. Antioxidant and anti-inflammatory studies proved the presence of therapeutic bioactive potential in the sample. Through in-silico analysis, docking studies were performed to confirm the functional role of the specific therapeutic phytochemical.

Conclusion: The fresh coconut sprouts are natural, economically potent food source for human health and can be a nutrient supplement with cost effective approach. The dried sprouts can also be recommended to the food industry for the large-scale production of nutrient-based foods with a quality check.

Keywords: Coconut sprouts, Phytochemical, Characterization, Antioxidant, Anti-inflammatory, In silico

(C) 2016 The Authors. Published by Innovare Academic Sciences Pvt Ltd. This is an open access article under the CC BY license (http://creativecommons.org/licenses/by/4. 0/) DOI: http://dx.doi.org/10.22159/ijpps.2017v9i3.16014

\section{INTRODUCTION}

Consumption of healthy food is highly essential to prevent various diseases. Formation of sprouts occurs from the seeds during sprouting. The sprouts are well known for its excellent source of essential nutrients like proteins, vitamins and minerals. The nutrient concentration of the sprouts remains very high when consumed at its growth phase. Along with the essential nutrients, the sprouts also contain enormous phytoconstituents. These phytoconstituents, vitamins, minerals, enzymes and amino acids are of great importance as these are the most prerequisites in maintaining human health [1-4]. The bioactive compounds found in the sprouts have a broad spectrum of anti-microbial, antioxidant and antiinflammatory properties [5].

The transformed protein content, the higher polyunsaturated fatty acid content, higher vitamin content and the better utilization of the minerals in the sprouts has a higher nutritional value and is of great biological importance. During the germination process, the polysaccharides degrade into oligosaccharides and mono-saccharides, the fats into free fatty acids and the proteins into oligopeptides and free amino acids, which support our biochemical mechanisms. These mainly improve the bio-efficiency of the protein-decomposing, carbohydrate and fatty acid decomposing enzymes; thereby the germination can be considered as a kind of pre-digestion which helps to break down the complex molecular substances into their building blocks.

Apart from leguminous seeds, some of the vegetables are also used for sprout production. Sprouted seeds are most commonly produced from adzuki beans, coconut, broccoli, buckwheat, cabbage, chickpeas, clover, cress, leek, lentils, linseed, mung beans, mustard, garlic, grass pea, green and yellow peas, onion, quinoa, radish, red beet, rice, rye, sesame, snow pea, soy, sunflower, fenugreek and wheat [6].
Sprouts are divided into sprouts, shoots or cress [6]. Sprouts are mainly germinated in water and collection is done before the development of leaves and the final product still contains the seed (except coconut sprout). Shoots are produced during germination in water which results in the formation of a green shoot with young leaves. The produced shoots are then harvested and consumed without the roots and seed. Cress is separately germinated in soil or using a hydrophobic substrate to produce green shoots with young leaves. But cress is commonly sold as an entire plant in its soil and the green shoots are harvested by the consumer.

Consuming sprouts provides enormous nutrients to our body. Various natural products produced from different plant sources are consumed directly as a food. Coconut sprout produced from Cocos nucifera L. with enormous nutrients is used as a natural edible product. It provides the necessary nutrition and improves our health aspects.

The constituents of $C$. nucifera $\mathrm{L}$. have some of the biological effects, such as anthelminthic, anti-inflammatory, antinociceptive, antioxidant, antifungal, antibacterial and antitumor activities. In addition, other properties such as anti-hypertensive, cardio-protective, anti-seizure, cytotoxicity, hepatoprotective, vasodilation, nephronprotective, and anti-osteoporosis effects were also reported. Because each part of $C$. nucifera has different phytoconstituents, the pharmacological and biological effects of the plant vary according to the parts of the plant evaluated [7].

During germination of the coconut, the basal part of the embryo, which is mainly embedded in the solid endosperm near the germinating pore, enlarges to form a cotyledonary structure called the sprout (haustorium). Coconut sprout is one of the edible parts of coconut. The coconut sprouts are spongy in nature, creamish or 
white or light yellowish in colour. It will be of great significance in the field of applied medicine due to its enormous amount of potential resources of phytoconstituents. The chemical analysis of the coconut sprout revealed the presence of proteins, vitamins, minerals and several secondary metabolites and can be used as a cardioprotective agent [8].

In general, the coconut sprouts have been consumed by different classes of people to reduce the risk of stomach problems. One such disorder which is peptic ulcer is caused by a bacteria, Helicobacter pylori or allergic reactions to some medicines like non-steroidal antiinflammatory drugs in the digestive tract in the stomach or the duodenum [9]. It is a gram-negative bacillus, motile, microaerophilic, flagellate bacteria. The pathogenic activity is found in the Type-I strains of the bacteria which encodes the effector protein cytotoxinassociated gene (cagA). After entering the host cell, cagA effects shape of the cell increases the cell motility, intrupt the cell junctional activity thereby resulting in gastric carcinomas and gastric ulcers [10]. The bacteria also causes an increase in the expression of cytokines like TNF- $\alpha$ gastritis, IL- $1 \beta$ is also overexpressed in gastritis [11]. H. pylori-infected gastric mucosa showed infiltration of polymorph nuclear leucocytes, lymphocytes, monocytes and plasma cells in the lamina propria and intraepithelial severe neutrophil infiltration [12]. The antibiotics at appropriate doses may result in a minimal chance for recurrence of ulcers. The bacterial infection can also be reduced through triple therapy regimens with proton pump inhibitor and two antibiotics such as amoxicillin and clithromycin may act as a standard therapy [13]. Peptic or stomach ulcers result in abdominal pain and discomforts. Some of the other symptoms include weight loss, nausea, poor appetite, bloating, blood in stool and vomiting, black stools indicating the gastrointestinal bleeding [14].

The main objective of the study was to analyze the medicinal properties, by giving scientific validation to the existing bioactive compounds present in the coconut sprouts and recommending the coconut sprouts as a natural product for the treatment of bacterial infection leading to inflammations. The sprouts are also enriched with various antioxidant, anticancer properties which increases the human nutrition thereby improving the health aspects. The various phytoconstituents makes the coconut sprouts to be rich in nutritive value and if consumed in the fresh or dried form of the coconut sprouts can be one of the economical sources for the betterment of human health.

\section{MATERIALS AND METHODS}

\section{Sample collection}

The fresh sprouts of Cocos nucifera L. were purchased from local markets in Chennai, Tamil Nadu. These fresh sprouts were used for further study. The analysis of dried samples was carried out with 100 gms of the coconut sprouts using dry shade method for three weeks. Then they were ground using a blender and stored in air tight containers for further analysis and were subjected to Soxhlet extraction with different solvents (fig. 1 and fig. 2).

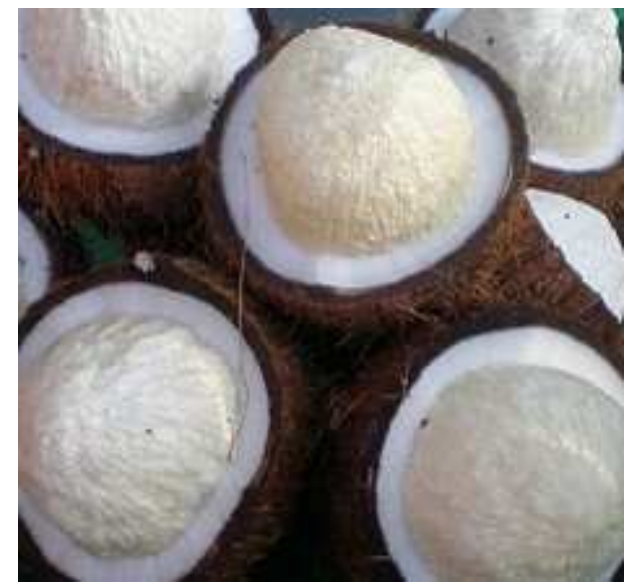

Fig. 1: Fresh coconut sprouts

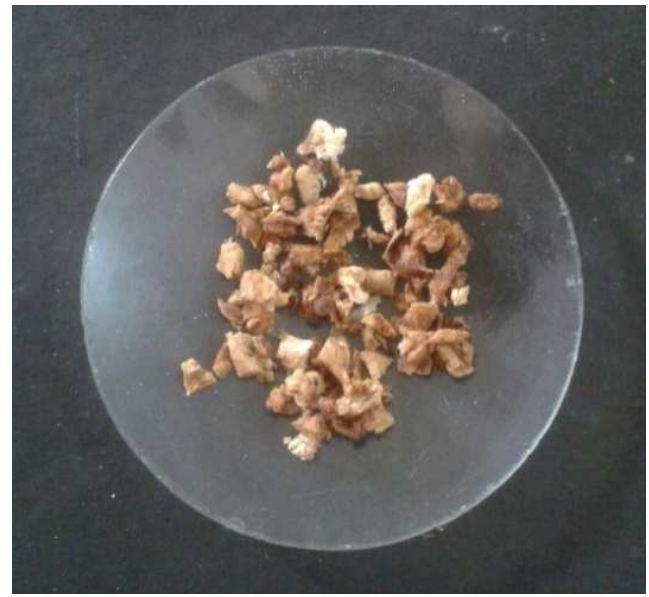

Fig. 2: Dried coconut sprouts

\section{Screening of microbial contamination}

During sprout production, the warm, humid and nutrient rich environment is ideal for bacterial growth. Since the sprouts are edible and used for consumption, the examination of microbial contamination is highly essential to analyse the purity of the samples [15]. The analysis was done to check whether the samples are pure which can be used for further tests and thereby recommended for consumption. The fresh and dried sprouts were checked for bacterial and fungal contamination. Serial dilution method was carried out for each sample. Dilutions of $10^{-6}$ and $10^{-7}$ were used for analysis for bacterial contamination and dilutions of $10^{-3}$ and $10^{-4}$ were used for analysis for fungal contamination. Nutrient Agar (NA) and Potato Dextrose Agar (PDA) plates were used for the analysis of bacterial and fungal contamination respectively using pour plate method. Nutrient Agar (NA) plates were incubated at $37^{\circ} \mathrm{C}$ and Potato Dextrose Agar (PDA) plates were kept in room temperature. The plates were observed after $24 \mathrm{~h}$ for any bacterial growth and $48 \mathrm{~h}$ for fungal growth.

\section{Crude extract preparation}

The crude extract preparation was carried out using $10 \mathrm{gms}$ of the fresh coconut sprouts was ground with $100 \mathrm{ml}$ of each of the solvents like butanol, acetone, methanol and water (aqueous) separately [16]. Then it was filtered using Whatmann No.1 filter paper and was centrifuged at $5000 \mathrm{rpm}$ for $15 \mathrm{~min}$. The supernatant was used for further phytochemical analysis. The powder (dried) was dissolved in different organic solvents namely (butanol, acetone, methanol and water) and filtered after $48 \mathrm{~h}$ for the dried sprouts analysis. The filtrates were then concentrated at 40 to $50{ }^{\circ} \mathrm{C}$ using a flash evaporator. The paste that was produced was freezedried and stored in a refrigerator in air tight containers for further analysis.

\section{Phytochemical screening}

The fresh and dried sprouts of Cocos nucifera L. butanol, acetone, methanol and aqueous extracts $(\mathrm{CB}, \mathrm{CAc}, \mathrm{CM}, \mathrm{CA}$ and $\mathrm{CBD}, \mathrm{CACD}$, CMD, CAD) were used for the phytochemical analysis. Qualitative phytochemical tests for the identification of alkaloids, saponins, terpenoids, glycosides, steroids and triterpenoids, resin, quinone, gum and mucilage, coumarin, anthraquinone, proteins and amino acids, anthocyanin and betacyanin, carbohydrates, phlobatannin, flavonoids, cardiac glycosides, phenols, tannins, phytosterol, polyphenols, fixed oils and fats, fatty acids were carried out for all the four extracts using standard protocols [17-20].

\section{Estimation and quantification}

The methanol and aqueous extracts of the fresh and dried coconut sprouts showed good results with the presence of various phytochemicals. These two extracts of the fresh and dried coconut sprouts were taken for further study. The estimation and quantification of the phytoconstituents such as proteins, terpenoids, 
total soluble sugars, flavonoids were carried out, and levels of phytic acid were quantified.

\section{Estimation of total soluble sugars}

The total soluble sugars were estimated using Dinitrosalicylic acid (DNS) method. $1 \mathrm{gm}$ of the sample was ground in $10 \mathrm{ml}$ of the solvents (methanol and aqueous). $1 \mathrm{ml}$ of the methanol and aqueous extracts (fresh and dried sprouts) were taken in the test tubes, to which $1 \mathrm{ml}$ of DNS reagent was added. The test tubes were placed in a boiling water bath for $5 \mathrm{~min}$ and were cooled to room temperature. Reagent blank was prepared similarly without the sample extract. The absorbance of the reddish coloured solution was measured at $575 \mathrm{~nm}$ using a UV Spectrophotometer. The amount of sugars in the extracts was calculated with the standard curve prepared from glucose $[21,22]$.

\section{Estimation of proteins}

Estimation of proteins was carried out using Lowry's method. The protein samples (fresh and dried) of both methanol and aqueous extracts (1 gm ground in $10 \mathrm{ml}$ of the solvent) were placed in $1 \mathrm{ml}$ of $1 \mathrm{~N}$ sodium hydroxide at $100^{\circ} \mathrm{C}$ for 4 to $5 \mathrm{~min}$ and $5 \mathrm{ml}$ of alkaline copper reagent was added, the mixture was allowed to stand at room temperature for $10 \mathrm{~min}$. $0.5 \mathrm{ml}$ of Folin-Ciocalteu reagent was added and mixed immediately. After $30 \mathrm{~min}$ the absorbance was measured at $750 \mathrm{~nm}$ using UV Spectrophotometer. The amount of protein in the samples were calculated with the standard curve prepared using Bovine Serum Albumin (BSA) or casein [23].

\section{Estimation of flavonoids}

The flavonoids were estimated using aluminium chloride method. $1 \mathrm{ml}$ of the methanol and aqueous extracts of the fresh and dried coconut sprouts were taken in the test tubes to which $0.3 \mathrm{ml}$ of $5 \%$ of sodium nitrite solution was added. After $5 \mathrm{~min}, 0.3 \mathrm{ml}$ of $10 \%$ aluminium chloride solution, $2 \mathrm{ml}$ of $1 \mathrm{M}$ sodium hydroxide solution was added. The absorbance of the yellowish coloured solution was measured at $510 \mathrm{~nm}$ using a UV Spectrophotometer. The amount of flavonoids was calculated using quercetin as standard $[24,25]$.

\section{Estimation of terpenoids}

The estimation of terpenoids was carried out using Ferguson's method. The fresh and dried sprouts of coconut $500 \mathrm{mg}$ were soaked in methanol and distilled water (aqueous) respectively for $24 \mathrm{~h}$ and filtered separately. Each filtrate was now extracted with petroleum ether. The resulting ether extract was treated as total terpenoids. The residue which was obtained was dried and weighed [26]. Then the terpenoid content was calculated using the formula:

Terpenoid content $(\%)=\frac{\text { Weight of terpenoid extract }(\mathrm{gms})}{\text { Weight of the sample }(0.5 \mathrm{gm})} \times 100$

\section{Estimation of phytic acid}

$1 \mathrm{gm}$ of each sample (fresh and dried) was homogenised with $20 \mathrm{ml}$ of $3 \%$ TCA. The homogenate was kept in the shaker for $30 \mathrm{~min}$. It was then centrifuged at $5000 \mathrm{rpm}$ for $10 \mathrm{~min}$. The pellet was discarded, and the supernatant was collected. $2 \mathrm{ml}$ of $1 \mathrm{~N}$ ferric chloride solution was added and mixed well.

This mixture was incubated in a hot water bath for $45 \mathrm{~min}$ and then centrifuged at $5000 \mathrm{rpm}$ for $10 \mathrm{~min}$. The supernatant was discarded and the precipitate obtained was dissolved in $10 \mathrm{ml}$ of $3 \%$ TCA. The obtained mixture was heated in a hot water bath for $5 \mathrm{~min}$ followed by centrifugation at $5000 \mathrm{rpm}$ for $10 \mathrm{~min} .2 \mathrm{ml}$ of water and $1.5 \mathrm{ml}$ of $1.5 \mathrm{~N}$ sodium hydroxide solution was added to the precipitate obtained and the volume was made up to $15 \mathrm{ml}$ using distilled water.

The mixture was kept in a hot water bath for $30 \mathrm{~min}$, cooled and filtered using Whatman No. 1 filter paper. The obtained precipitate was washed several times with hot water and dissolved in $10 \mathrm{ml}$ hot $3.2 \mathrm{~N}$ hydrochloric acid. Cool the content to room temperature and dilute with $10 \mathrm{ml}$ of water. Absorbance was measured at $480 \mathrm{~nm}$ using UV Spectrophotometer. Iron content from $\mathrm{Fe}\left(\mathrm{NO}_{3}\right)_{3}$ standard was calculated. Phytate phosphorus from the iron results was calculated [27].

\section{Fourier transform infrared spectrophotometer (FT-IR) analysis}

For the FT-IR study, Spectrum FT-IR system (Shimadzu, IR Affinity 1, Japan), equipped with a DLATGS detector with a mirror speed of $2.8 \mathrm{~mm} / \mathrm{sec}$. scan range: from $400-4000 \mathrm{~cm}^{-1}$ with a resolution of 4 $\mathrm{cm}^{-1}$ was used. The methanol and aqueous extracts of the fresh and dried coconut sprouts were prepared. The extracts were evaporated by the flash evaporator and it was mixed with a $\mathrm{KBr}$ salt, using a mortar and pestle and compressed into a thin pellet. Infrared spectra were recorded on $\mathrm{KBr}$ pellet on a Shimadzu FTIR spectrometer $4000-500 \mathrm{~cm}^{-1}$.

\section{Antibacterial assay}

The antibacterial study was carried out with methanol and aqueous extracts of the fresh coconut sprouts. Different concentrations of the extracts of the samples $(50 \mu \mathrm{g}, 75 \mu \mathrm{g}, 100 \mu \mathrm{g})$ were assayed against Staphylococcus aureus, Escherichia coli, Salmonella typhi, Klebsiella pneumoniae and Shigellaflexneri (Bacterial cultures were obtained from Department of Microbiology, Ethiraj College for Women, Chennai) were used. Antibacterial assay was carried out by a well diffusion method using Mueller-Hinton agar media. Streptomycin was used as positive control. The plates were incubated at $37^{\circ} \mathrm{C}$ for bacterial growth. Zone of inhibition around the well was observed after $24 \mathrm{~h}$ for antibacterial assay. Triplicates were maintained for all the samples.

\section{In vitro anti-inflammatory assay (Inhibition of the albumin denaturation)}

The reaction mixture consisting of fresh and dried sample extracts (methanol and aqueous) of different concentrations (100-500 $\mu \mathrm{g}$ ) and $1 \%$ aqueous solution of bovine albumin fraction were prepared. Diclofenac sodium $(10 \mathrm{mg})$ was used as a standard drug. The sample extracts and standard were incubated at $37^{\circ} \mathrm{C}$ for $20 \mathrm{~min}$ and then heated to $51^{\circ} \mathrm{C}$ for $20 \mathrm{~min}$. After cooling the samples, the turbidity was measured using a UV Spectrophotometer at $660 \mathrm{~nm}$. The experiment was performed in triplicates $[28,29]$. Percent inhibition of protein denaturation was calculated as follows,

$$
\% \text { Inhibition }=\frac{\text { Control OD }- \text { Test OD }}{\text { Control OD }} \times 100
$$

Where Control OD is the absorbance without a sample, Test OD is the absorbance of sample extract/standard.

\section{Determination of antioxidant activity}

\section{Hydrogen peroxide scavenging assay}

The Hydrogen peroxide $\left(\mathrm{H}_{2} \mathrm{O}_{2}\right)$ scavenging activity was determined using the standard method [30]. The methanol and aqueous extracts of the fresh and dried coconut sprouts of various concentrations from $100-500 \mu \mathrm{g}$ were prepared. Extracts of $0.1 \mathrm{ml}$ of each concentration, were dissolved in $3.4 \mathrm{ml}$ of $0.1 \mathrm{M}$ phosphate buffer (pH-7.4) and mixed with $0.6 \mathrm{ml}$ of 43 mmol hydrogen peroxide solution. Using a UV Spectrophotometer, the absorbance of the reaction mixture was read at $230 \mathrm{~nm}$. Phosphate buffer without hydrogen peroxide solution was used as a blank. The inhibition was calculated and recorded. Ascorbic acid was used as a standard. The hydrogen peroxide scavenging activity of the sprout extracts was calculated using a formula:

Hydrogen peroxide scavenging effect $(\%)=\mathrm{Ac}-\mathrm{Ao} / \mathrm{Ac} \times 100$

Where $A_{c}$ is the absorbance of control, $A_{o}$ is the absorbance of sprout extract.

\section{Reducing power assay}

The reducing power of the fresh and dried coconut sprouts methanol and aqueous extracts were evaluated using standard method [31]. Different concentrations of the samples $(100-500 \mu \mathrm{g})$ were prepared to which $2.5 \mathrm{ml}$ of phosphate buffer (pH-6.6) was added. Then $2.5 \mathrm{ml}$ of $1 \%$ potassium ferricyanide solution was added and mixed well. This mixture was kept at $50{ }^{\circ} \mathrm{C}$ in a water bath for $20 \mathrm{~min}$. After cooling the test tubes, $2.5 \mathrm{ml}$ of $10 \%$ trichloroacetic acid was added and centrifuged at $3000 \mathrm{rpm}$ for 10 min. $2.5 \mathrm{ml}$ of the supernatant was mixed with $2.5 \mathrm{ml}$ of distilled water and $0.5 \mathrm{ml}$ of $0.1 \%$ ferric chloride solution and the mixture 
was kept undisturbed for $10 \mathrm{~min}$. The absorbance of the resulting solution was measured at $700 \mathrm{~nm}$ using a UV Spectrophotometer. The increase in absorbance of the reaction mixture indicates increased reducing power. The experiment was conducted in triplicates and values were expressed as equivalents of ascorbic acid in $\mu \mathrm{g} / \mathrm{mg}$ of the extract.

\section{DPPH radical scavenging assay}

Free radical scavenging activity of the methanol and aqueous extracts of the fresh and dried coconut sprouts were measured by 1 , 1-diphenyl-2-picrylhydrazyl (DPPH). $0.1 \mathrm{mmol}$ solution of DPPH in methanol was prepared. $1 \mathrm{ml}$ of DPPH was added to $3 \mathrm{ml}$ of sample extracts (methanol and aqueous extracts) of different concentrations of $100,200,300,400,500 \mu \mathrm{g} / \mathrm{ml}$. The above mixture was shaken vigorously and allowed to stand at room temperature for $30 \mathrm{~min}$. The absorbance was measured at $517 \mathrm{~nm}$ in UV Spectrophotometer [32]. The experiment was carried out using ascorbic acid as the reference standard [33]. The DPPH scavenging effect was calculated using the following equation:

$$
\begin{gathered}
\text { DPPH scavenging effect }(\%) \text { or Percent inhibtion } \\
=\mathrm{A} 0-\mathrm{A} 1 / \mathrm{A} 0 \times 100
\end{gathered}
$$

Where $A_{0}$ was the absorbance of control and $A_{1}$ was the absorbance of the standard or test sample [34].

\section{Thin layer chromatography (TLC) analysis}

Commercially prepared TLC sheets of $20 \times 20 \mathrm{~cm}$ pre-coated silica gel (Kieselgel 60 F254 DC-Aluofolein) was used. The sheet was cut into a size of $10 \times 10 \mathrm{~cm}$ and the extracts were spotted at the bottom of the TLC sheet (about $1 \mathrm{~cm}$ from base). The sheet was then placed in a developing tank containing the chosen solvent system [35]. TLC studies were carried out using fresh coconut sprouts methanol extract which showed potent results. The crude extracts of the fresh coconut sprouts were spotted onto the TLC sheet. The solvent system used for TLC were, Proteins-n-butanol: Pyridine: Water (1:1:1), Terpenoids-Chloroform: Methanol: Water $(30: 4: 1 \mathrm{v} / \mathrm{v})$, Flavonoids-Chloroform: Methanol (96:4). The chromatogram sheet was placed inside the solvent chamber. Then it was allowed to run until it reached $3 / 4$ position. Ninhydrin solution $(0.2 \%)$ was used as spraying reagent. After spraying, the sheet was allowed to dry. The spots were noted and Rf values were calculated using the formula for different phytoconstituents:

\section{Rf value}

$=$ Distance travelled by the solute/Distance travelled by the solvent

\section{Gas chromatography-mass spectrometry (GC-MS) analysis}

\section{Gas chromatograph}

$100 \mu \mathrm{l}$ methanol extract of fresh coconut sprouts (CM) was used for GC-MS analysis. A Shimadzu GC-2010 Plus gas chromatograph was equipped with a straight deactivated $2 \mathrm{~mm}$ direct injector liner and a $15 \mathrm{~m}$ Alltech EC-5 column $(250 \mu$ I.D., $0.25 \mu$ film thickness). A split injection was used for sample introduction and the split ratio was set to $10: 1$. The oven temperature program was programmed to start at $35{ }^{\circ} \mathrm{C}$, hold for $2 \mathrm{~min}$, then ramp at $20^{\circ} \mathrm{C}$ per minute to 450 ${ }^{\circ} \mathrm{C}$ and hold for $5 \mathrm{~min}$. The helium carrier gas was set to $2 \mathrm{ml} / \mathrm{minute}$ flow rate (constant flow mode).

\section{Mass spectrum}

A direct connection with capillary column metal quadupole mass filter pre-rod mass spectrometer operating in electron ionization (EI) mode with software GCMS solution ver. 2.6 was used for all analyses. Low-resolution mass spectra were acquired at a resolving power of 1000 ( $20 \%$ height definition) and scanning from m/z 25 to $\mathrm{m} / \mathrm{z} 1000$ at 0.3 seconds per scan with a 0.2 -second inter-scan delay. High-resolution mass spectra were acquired at a resolving power of 5000 (20\% height definition) and scanning the magnet from $\mathrm{m} / \mathrm{z} 65$ to $\mathrm{m} / \mathrm{z} 1000$ at 1 second per scan.

\section{Mass spectrometry library search}

Identification of the components of the compound was matched with their recorded spectra from the data bank mass spectra of NIST library V 11 provided by the instrument's software. GC/MS metabolomics Database was used for the similarity search with retention index.

\section{In silico analysis (Docking studies)}

In silico analysis through molecular docking helps us to study the functional role of the specific bioactive compound. The compounds identified by GC-MS analysis in the coconut sprouts were screened against the target protein (Helicobacter pylori). The target molecule was retrieved from (PDB) Protein Data Bank (http://www. rcsb.org/pdb/). The bioactive compound details were retrieved from the Pubchem database. The bioactive compounds were docked against the target protein in mcule database. Docking results in interactions between the target and ligand molecules. Docking studies were carried out to prove the anti-inflammatory property of the bio-constituent from the sprout samples. Diclofenac sodium was used as a standard anti-inflammatory compound [36].

\section{Statistical analysis}

For each experiment, data presented are the means of three replicates. Values are expressed as mean $\pm \mathrm{SD}$ of three replicates.

\section{RESULTS AND DISCUSSION}

The sprouted foods are normally consumed by all classes of people. Specifically, the consumption of sprouted coconut is in the day to day practice by the common people seen in different parts of Chennai, Tamil Nadu for curing inflammation in the stomach. The coconut sprouts are known to be an excellent source of phytoconstituents such as proteins, vitamins, minerals and several secondary metabolites. Study of various medicinal properties of coconut sprouts leads to the betterment of human health aspects by discovering their antimicrobial, anti-inflammatory, antioxidant and anti-ulcer properties as not much work is carried out and not proven scientifically.

\section{Screening of microbial contamination}

The coconut sprouts were examined for microbial contamination in order to check the purity of the samples used after $24 \mathrm{~h}$ and $48 \mathrm{~h}$, where after $24 \mathrm{~h}$, the microbial population was found to be nil and following are the results recorded after $48 \mathrm{~h}$. Results revealed that coconut sprouts were found to be pure (table 1).

Table 1: Screening of microbial contamination of fresh coconut sprouts

\begin{tabular}{llllll}
\hline S. No. & Sample & Bacteria & & \multicolumn{2}{c}{ Fungi } \\
\cline { 3 - 5 } & & Control & $\mathbf{1 0}^{-\mathbf{6}}$ & $\mathbf{1 0}^{-\mathbf{7}}$ & $\mathbf{C o n t r o l ~}^{-\mathbf{1}}$ \\
\hline 1. & Fresh Coconut sprouts & - & - & - & - \\
2. & Dried Coconut sprouts & - & - & - & - \\
\hline
\end{tabular}

Enhanced reductions of total aerobic mesophilic bacteria, total and faecal coliforms and yeast and moulds populations were observed with increased pressure and temperature mung bean and alfalfa seeds [37]. Thus, the study revealed that the reduced level of microbial load, may be attributed to the complete sterilization maintained from the processing (germination, drying and powdering) of the seeds for sprouting which is of great significance in maintaining the quality of the sample used since the samples are edible either in fresh or dried form.

\section{Phytochemical screening}

The phytochemical analysis carried out (fresh and dried coconut sprouts) using different solvents namely butanol, acetone, methanol 
and aqueous (water) revealed the presence of phytoconstituents chiefly in methanol and aqueous solvents.

The fresh and dried coconut sprouts indicated the presence of alkaloids, saponins, terpenoids, steroids, triterpenoids, resin, quinone, proteins, amino acids, carbohydrates, flavonoids, cardiac glycosides, phenols, tannins, fixed oils, fats and fatty acids.

The fresh coconut sprouts only showed the presence of betacyanin (table 2).

Table 2: Phytochemical analysis of various solvent extracts of fresh and dried coconut sprouts

\begin{tabular}{|c|c|c|c|c|c|c|c|c|c|}
\hline \multirow[t]{2}{*}{ S. No. } & \multirow[t]{2}{*}{ Phytochemical constituents } & \multicolumn{2}{|c|}{ Butanol } & \multicolumn{2}{|c|}{ Acetone } & \multicolumn{2}{|c|}{ Methanol } & \multicolumn{2}{|c|}{ Aqueous } \\
\hline & & $\mathbf{F}$ & D & $\mathbf{F}$ & $\mathbf{D}$ & $\mathbf{F}$ & D & $\mathbf{F}$ & $\mathbf{D}$ \\
\hline 1. & Alkaloids & - & - & - & - & - & - & + & + \\
\hline 2. & Saponins & + & + & + & + & + & + & + & + \\
\hline 3. & Terpenoids & + & + & + & + & + & + & + & + \\
\hline 4. & Glycosides & - & - & - & - & - & - & - & - \\
\hline 5. & Steroids and Triterpenoids & + & + & + & + & + & + & + & + \\
\hline 6. & Resin & + & + & + & + & + & + & + & + \\
\hline 7. & Quinone & + & + & + & + & + & + & + & + \\
\hline 8. & Gum and Mucilage & - & - & - & - & - & - & - & - \\
\hline 9. & Coumarin & - & - & - & - & - & - & - & - \\
\hline 10. & Anthroquinone & - & - & - & - & - & - & - & - \\
\hline 11. & Protein and Amino acids & + & + & + & + & + & + & + & + \\
\hline 12. & Anthocyanin and Betacyanin & + & - & + & - & + & - & + & - \\
\hline 13. & Carbohydrates & + & + & + & + & + & + & + & + \\
\hline 14. & Phlobatannin & - & - & - & - & - & - & - & - \\
\hline 15. & Flavonoids & - & - & + & - & + & + & + & + \\
\hline 16. & Cardiac glycosides & + & - & + & - & + & - & + & + \\
\hline 17. & Phenols & - & - & - & - & + & - & + & - \\
\hline 18. & Tannins & - & - & + & - & - & - & + & + \\
\hline 19. & Phytosterols & - & - & - & - & - & - & - & - \\
\hline 20. & Polyphenols & - & - & - & - & - & - & - & - \\
\hline 21. & Fixed oils and fats & - & - & - & - & - & - & + & + \\
\hline 22. & Fatty acids & - & - & - & - & - & - & + & + \\
\hline
\end{tabular}

(F)-Fresh; (D)-Dried; (+) presence; (-) absence

The novel phytoconstituents are of great significance in improving human health aspects. The major food nutrients such as proteins, free amino acids and carbohydrates present in the sprouts enhance the nutritional quality. The terpenoids have high antioxidant potential, also used as an anti-inflammatory agent, antibacterial and anti-viral agent $[38,39]$. Saponins are non-volatile surfactants with antimicrobial, anti-inflammatory and anti-tumour properties. Steroids are mainly used in the treatment of asthma, skin inflammation, hormone control. The cardiac glycosides act as a cardioprotective agent. The various other phytochemicals such as alkaloids, flavonoids, resin, quinone, triterpenoids, anthocyanin, betacyanin, tannins, fatty acids, fixed oils and fats also makes the sprout as a healthy edible product by acting against various human pathogens thereby benefiting the human health.

\section{Estimation and quantification}

The total soluble sugars were quantified in the fresh and dry coconut sprouts. The standard solution of concentration $(10-100 \mathrm{ppm})$ confirmed to Beer's Law at $510 \mathrm{~nm}$ with a regression coefficient $\left(\mathrm{R}^{2}\right)$ $=0.9918$. The plot has a slope $(\mathrm{m})=0.0078$ and intercept $=0.0577$. The equation of the standard curve is $y=0.0078 x+0.0577$. The results revealed that methanol and aqueous extract of fresh coconut sprouts had $0.60 \pm 0.1 \mathrm{mg} / \mathrm{g}$ and $0.58 \pm 0.2 \mathrm{mg} / \mathrm{g}$ of glucose and the dried coconut sprouts had $0.57 \pm 0.2 \mathrm{mg} / \mathrm{g}$ and $0.56 \pm 0.1 \mathrm{mg} / \mathrm{g}$ of glucose.

Protein content in various sprout samples was estimated using BSA as standard. The standard solution of concentration (100-1000 $\mathrm{ppm}$ ) confirmed to Beer's Law at $510 \mathrm{~nm}$ with a regression coefficient $\left(R^{2}\right)=0.9901$. The plot has a slope $(m)=0.0008$ and intercept $=0.0614$. The equation of standard curve is $\mathrm{y}=$ $0.0008 x+0.0614$. The results indicated that methanol and aqueous extract of fresh coconut sprouts had $39 \pm 0.8 \mathrm{mg} / \mathrm{ml}$ and $38 \pm 1.2$ $\mathrm{mg} / \mathrm{ml}$ of protein and the dried coconut sprouts had $36 \pm 0.9 \mathrm{mg} / \mathrm{ml}$ and $35 \pm 1.1 \mathrm{mg} / \mathrm{ml}$ of protein.

Quantification of flavonoids carried out in fresh and dried samples. The quercetin solution of concentration (100-1000 ppm) confirmed to Beer's Law at $510 \mathrm{~nm}$ with a regression coefficient $\left(\mathrm{R}^{2}\right)=0.9933$. The plot has a slope $(\mathrm{m})=0.0008$ and intercept $=0.0495$. The equation of standard curve is $y=0.0008 x+0.0495$. The results revealed that methanol and aqueous extract of fresh coconut sprouts had $0.28 \pm 0.1 \mathrm{mg} \mathrm{QE} / \mathrm{g}$ and $0.25 \pm 0.12 \mathrm{mg} \mathrm{QE} / \mathrm{g}$ and the dried coconut sprouts had $0.23 \pm 0.13 \mathrm{mg} \mathrm{QE} / \mathrm{g}$ and $0.22 \pm 0.008 \mathrm{mg} \mathrm{QE} / \mathrm{g}$.

Terpenoid content in the fresh and dry sprouts was quantified. The results revealed that methanol and aqueous extract of fresh coconut sprouts had $95 \pm 1.2 \mathrm{mg} / \mathrm{g}$ and $90 \pm 1.1 \mathrm{mg} / \mathrm{g}$ and the dried coconut sprouts had $89 \pm 1.1 \mathrm{mg} / \mathrm{g}$ and $85 \pm 1.3 \mathrm{mg} / \mathrm{g}$.

Investigation studies on proteins and carbohydrates carried out in methanol extracts of Triticum aestivum $3 \mathrm{~d}$ old seedlings and wheat grains revealed $326 \mathrm{mg} / \mathrm{g}$ of protein, $36.792 \mathrm{mg} / \mathrm{g}$ of carbohydrates in $3 \mathrm{~d}$ old wheat seedlings and $305.84 \mathrm{mg} / \mathrm{g}$ of protein, $46.14 \mathrm{mg} / \mathrm{g}$ of carbohydrates in wheat grains [40]. Quantification of protein content of selected samples of Glycine max with respect to BSA was found to be $90.6 \mu \mathrm{g} / \mathrm{ml}, 82 \mu \mathrm{g} / \mathrm{ml}, 94.5 \mu \mathrm{g} / \mathrm{ml}$ and $79.1 \mu \mathrm{g} / \mathrm{ml}$ respectively [41]. Thus the results are also clear evidence that sprouting enhanced the amount of carbohydrates, protein content and various other bio-constituents like flavonoids, terpenoids making the sprouts highly nutritious than the seeds.

Phytic acid content in the fresh and dry sprouts was estimated which showed that methanol and aqueous extract of fresh coconut sprouts had $0.12 \pm 0.009 \mathrm{mg} / \mathrm{g}$ and $0.13 \pm 0.006 \mathrm{mg} / \mathrm{g}$ and the dried coconut sprouts had $0.13 \pm 0.007 \mathrm{mg} / \mathrm{g}$ and $0.12 \pm 0.008 \mathrm{mg} / \mathrm{g}$.

The total amount of nutrients, levels of anti-nutritive factors determines the nutritional quality of the food consumed. One such anti-nutritional factor, 'phytic acid' (myoinositol hexakis--dihydrogenphosphate), is a major storage form of organic phosphorous in legumes, cereals, oilseeds and nuts. Due to its chelation of various cations, in humans, reduction in the digestibility of proteins, starch and lipids occurs. The enzyme 'phytase' (myoinositol-hexaphosphate phosphohydrolase) belonging to acid phosphatases have the capacity to hydrolyze phytic acid to a series of lower phosphate esters of myoinositol and phosphate. The phytase enzyme 
contributes to the food industry by decreasing the levels of phytic acid in the food and making the food safer for consuming. In plants,the enzyme is produced by various cereals and legumes and from microbes such as Aerobacter, Bacillus, Klebsiella sp. During sprouting, the production of phytases occurs which decreases the levels of phytic acid [42]. The levels of a phytic acid depend on the amount of plant-derived foods in the diet and food processing, the daily intake of phytate can be as high as $4500 \mathrm{mg}$ [43]. In average, the daily intake of phytic acid was estimated to be 2000-2600 mg for vegetarian diets as well as diets of inhabitants of rural areas of developing countries and 150-1400 mg for mixed diets. The results showed the decreased levels of phytic acid content when compared to the seeds.

\section{Fourier transform infrared spectrophotometer (FT-IR) analysis}

FT-IR analysis of all the fresh and dry sprouts reveals about the distribution of functional groups within the organic fractions and provides a basis for a comparison of compositional differences between the sprouts.

The FT-IR spectra for fresh coconut sprouts methanol extract (CM) showed the presence of various functional groups such as alkyl halides, esters, carboxylic acids, alkenes, amides, ketones, alkynes, alkanes and alcohols (fig. 3). The FT-IR spectra for fresh coconut sprouts aqueous extract (CA) showed the presence of various functional groups such as alkyl halides, alkenes, alkanes, esters, ketones, alkynes, phosphines, phosphoric acid, carboxylic acids and alcohols (fig. 4). The FT-IR spectra for dried coconut sprouts methanol extract (CMD) showed the presence of various functional groups such as alkyl halides, alkynes, esters, carboxylic acids, amides, ketones, phosphines and alkanes (fig. 5). The FT-IR spectra for dried coconut sprouts aqueous extract (CAD) showed the presence of various functional groups such as alkyl halides, alkynes, alkanes, carboxylic acids, ketones, isocyanides, phosphines, aldehydes and alcohols (fig. 6).

The results revealed terpenoids were found to be present because of the presence of $\mathrm{C}-\mathrm{H}$ stretch at 2862.49 and $2928.07 \mathrm{~cm}^{-1}$. The presence of $\mathrm{C}=0$ stretch at $1743.72 \mathrm{~cm}^{-1}$ showed the presence of saponins [44]. The presence of different functional groups may be attributed to the existence of a variety of potential phytochemicals. The multiple functional groups reflect either the complex structure or it indicates the nature of the sample as a mixture.

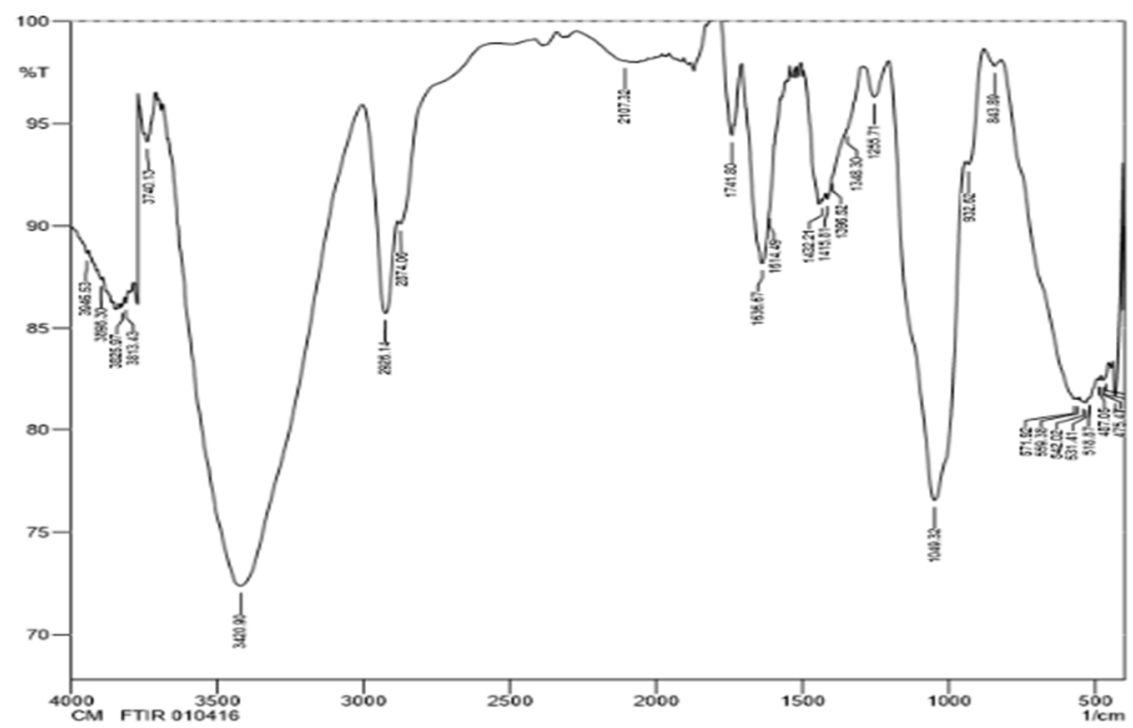

Fig. 3: FT-IR Spectrum of fresh coconut sprouts methanol extract (CM)

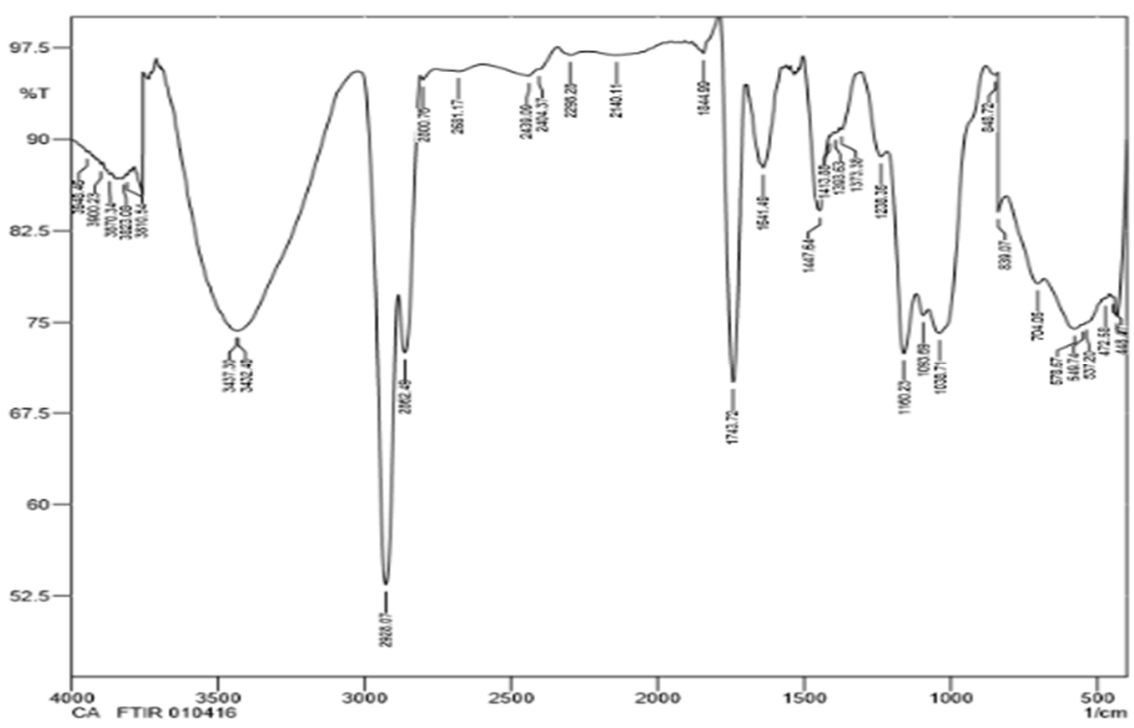

Fig. 4: FT-IR spectrum of fresh coconut sprouts aqueous extract (CA) 


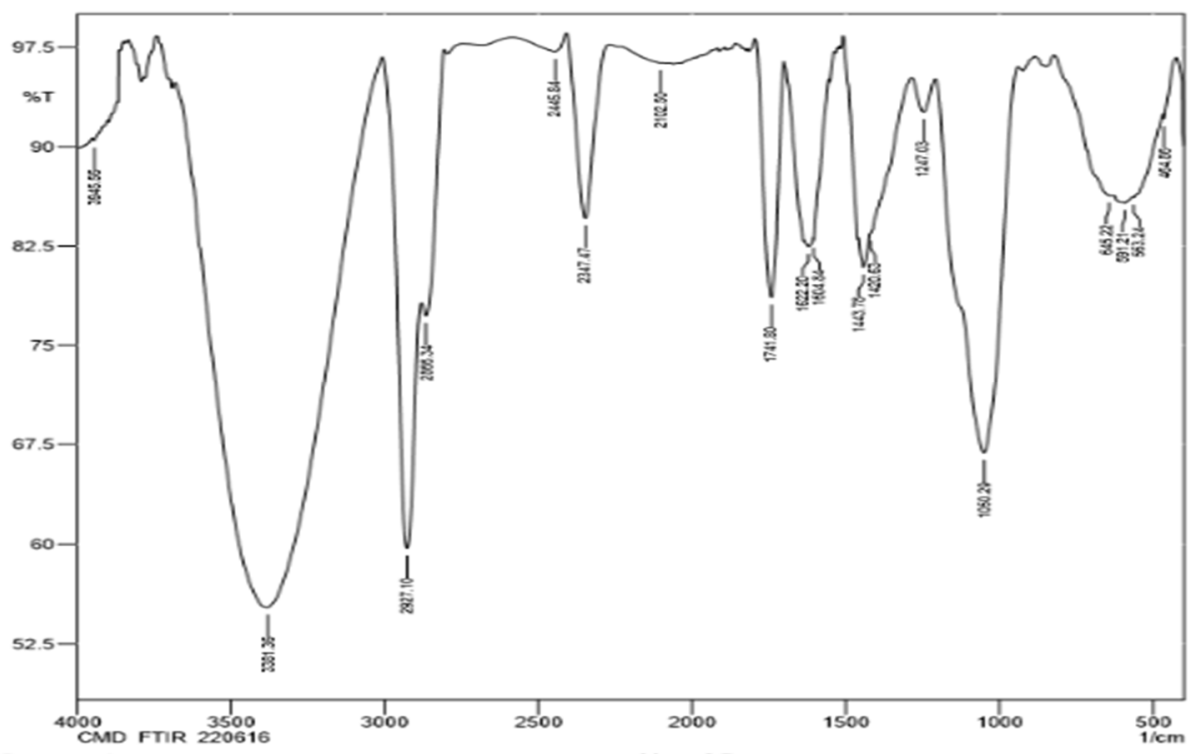

Fig. 5: FT-IR spectrum of dried coconut sprouts methanol extract (CMD)

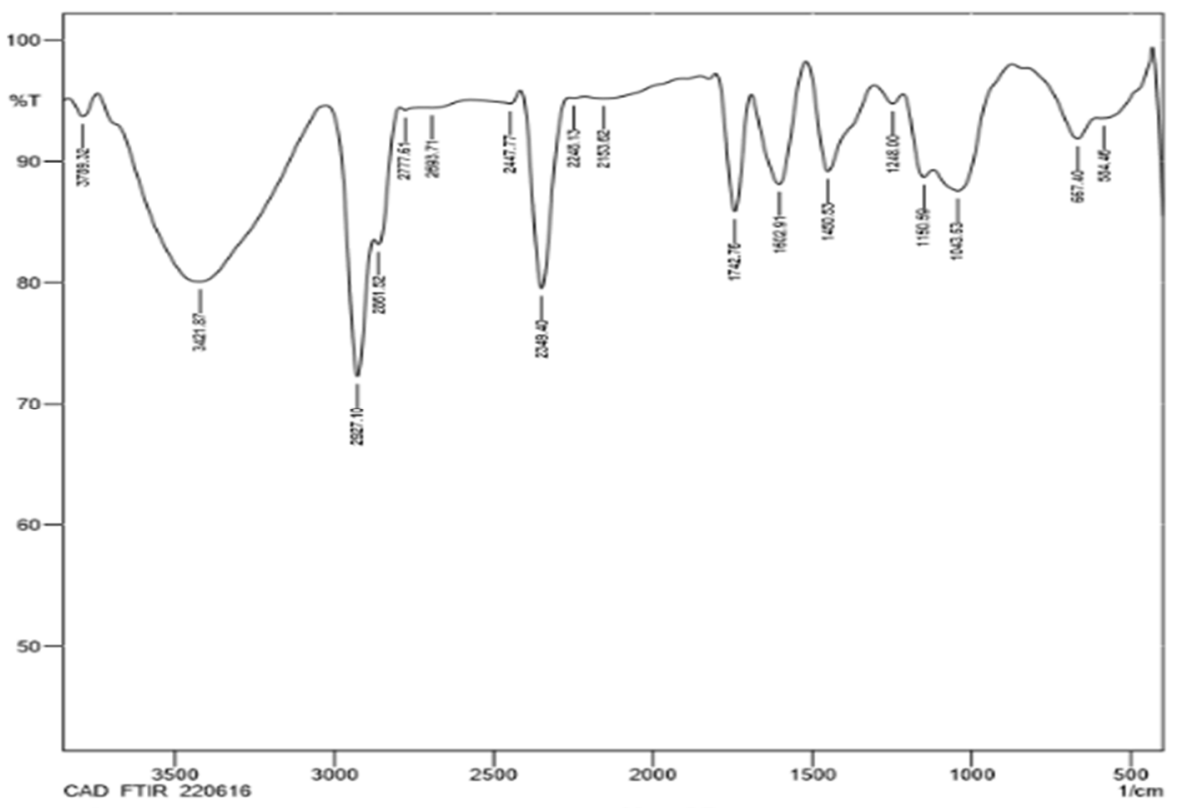

Fig. 6: FT-IR spectrum of dried coconut sprouts aqueous extract (CAD)

\section{Antibacterial assay}

The methanol extract of fresh coconut sprouts (CM) at $100 \mu \mathrm{g}$ showed a maximum zone of inhibition $(32 \pm 0.6 \mathrm{~mm})$ against Shigella flexneri and minimum zone of inhibition $(5 \pm 0.1 \mathrm{~mm})$ against Escherichia coli (fig. 7 and fig. 8). Aqueous extract of fresh coconut sprouts (CA) at $100 \mu \mathrm{g}$ showed a maximum zone of inhibition (31 \pm 0.5 $\mathrm{mm})$ against Shigella flexneri and minimum zone of inhibition $(5 \pm 0.3$ $\mathrm{mm}$ ) against Escherichia coli (fig. 9 and fig. 10).

The minimum inhibition zone was found against $E$. coli, reveals that the intake of these sprouts will not bring down the natural microbial flora of the intestine when consumed fresh. The dried sprouts were also tested against the human pathogens, and only minimum zone of inhibition was observed whereas fresh sprouts showed maximum antibacterial activity. The presence of potent phytoconstituents like terpenoids and flavonoids might be responsible for the prominent antibacterial activity of the coconut sprouts.

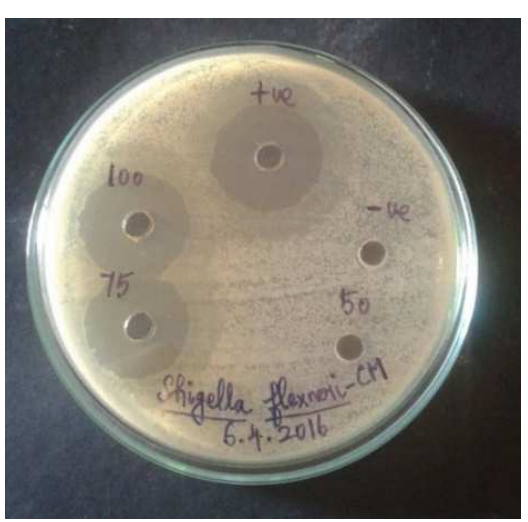

Fig. 7: Maximum zone of inhibition of fresh coconut sprout methanol extract (CM) against Shigella flexneri 


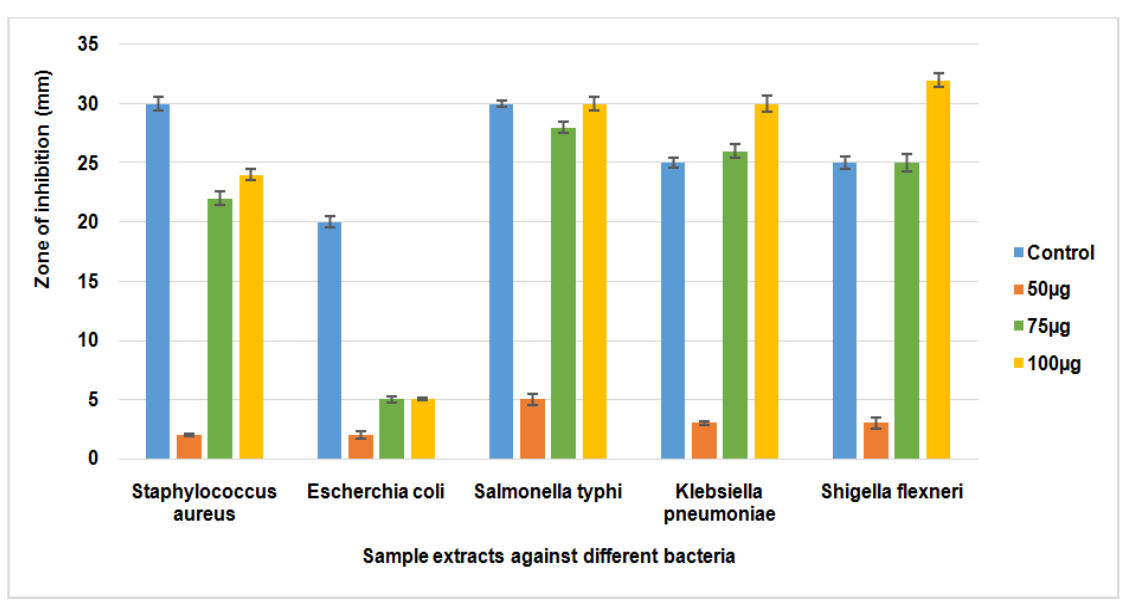

Fig. 8: Antibacterial activity of fresh coconut sprout methanol extract (CM) of different concentrations against different foodborne pathogenic bacteria

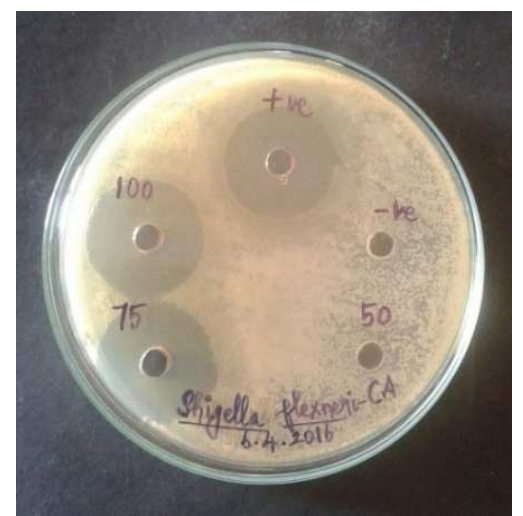

Fig. 9: Maximum zone of inhibition of fresh coconut sprout aqueous extract (CA) against Shigella flexneri

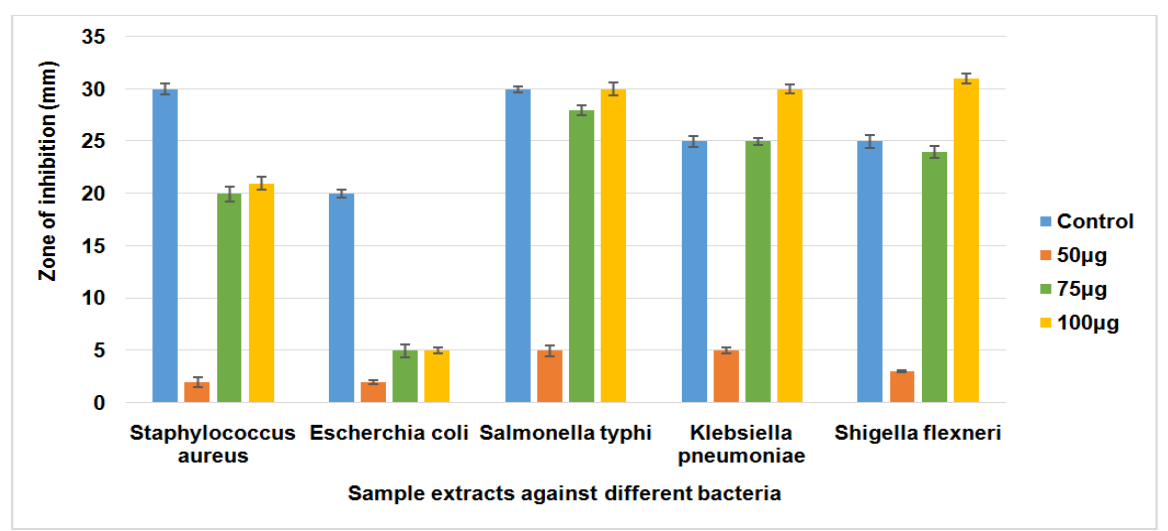

Fig. 10: Antibacterial activity of fresh coconut sprouts aqueous extract (CA) against different foodborne pathogenic bacteria

Food safety research is mainly concerned with growing number of disease outbreaks caused by various pathogenic and spoilage microorganisms in foods. Foodborne illness also has a major economic impact on society generally cause temporary disorders of the digestive tract; however, they can also lead to serious consequences [45]. In recent years, a number of widely reported outbreaks of foodborne illness caused by microbial contamination have increased public awareness and concern about the safety of food. The increasing antibiotic resistance of some pathogens that are associated with foodborne illness is another concern [46]. In the natural environment, sprouts survive during germination by enhancing their defensive responses through vitamins, enzymes, and receptor [47]. The antimicrobial defences might be highly involved among the enhanced defensive mechanisms during germination. The use of phytoconstituents as a natural antimicrobial agent which is commonly called 'biocides' are gaining popularity in recent times [48]. The results clearly showed that the sprouts can act as a potent antibacterial agent against several human pathogens. The phytoconstituents of the sprouts (carbohydrates, proteins, terpenoids, flavonoids) are mainly responsible for promoting the zone of inhibition against the human foodborne pathogens. Consuming sprouts as food is a preventive measure in the management of foodborne pathogenic bacteria and this will be beneficial in resistance towards any foodborne diseases. 
In vitro anti-inflammatory assay (inhibition of the albumin denaturation)

The anti-inflammatory assay was carried out at different concentrations $(100,200,300,400,500 \mu \mathrm{g})$ of methanol and aqueous extracts of fresh and dried coconut sprouts. Results revealed inhibition of thermally-induced protein (albumin) denaturation in a dose-dependent manner. The anti-inflammatory potential of different samples are determined based on their $\mathrm{IC}_{50}$ value. The $\mathrm{IC}_{50}$ value is the measure of the extract concentration that is required for $50 \%$ inhibition. LesserIC $C_{50}$ value denotes the higher anti-inflammatory potential of the sprouts.
The fresh coconut sprouts methanol extract (CM) and aqueous extract (CA) showed per cent maximum inhibition of $85 \pm 1.2$ and $81 \pm 1.3$ respectively at a $500 \mu \mathrm{g}$ concentration with $\mathrm{IC}_{50}$ value of $211.9 \mu \mathrm{g} / \mathrm{ml}$ and $250.7 \mu \mathrm{g} / \mathrm{ml}$ (fig. 11). The dried coconut sprouts methanol extract (CMD) and aqueous extract (CAD) showed per cent maximum inhibition of $80 \pm 1.6$ and $79 \pm 1.2$ respectively at a $500 \mu \mathrm{g}$ concentration with $\mathrm{IC}_{50}$ value of $244.3 \mu \mathrm{g} / \mathrm{ml}$ and $265.2 \mu \mathrm{g} /$ $\mathrm{ml}$ (fig. 12).

The anti-inflammatory activity of standard diclofenac sodium showed per cent maximum inhibition $90 \pm 1.5$ at a $500 \mu \mathrm{g}$ concentration with $\mathrm{IC}_{50}$ value of $125.8 \mu \mathrm{g} / \mathrm{ml}$.

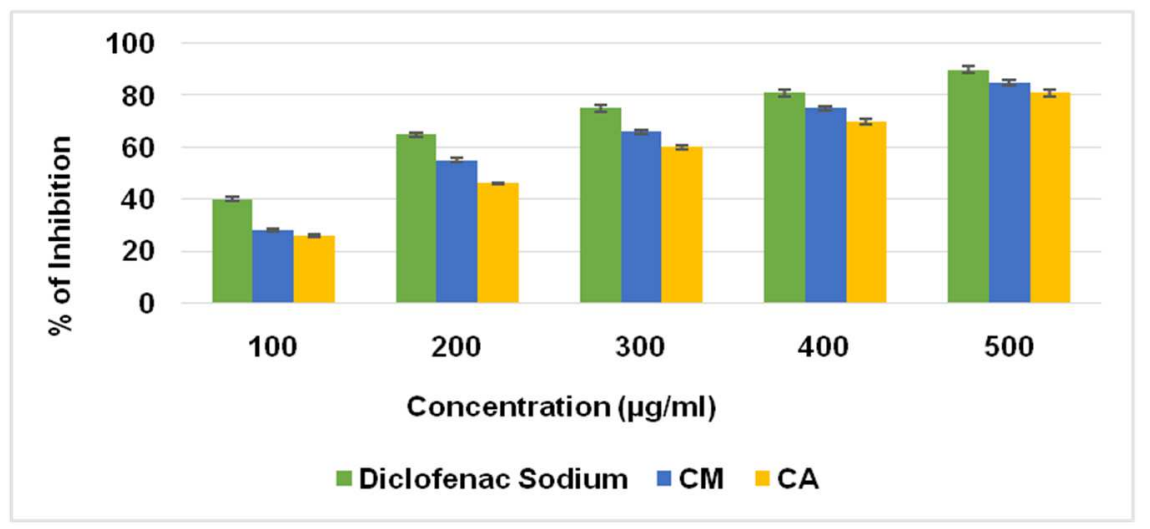

Fig. 11: Anti-inflammatory activity of fresh coconut sprouts methanol extract (CM) and aqueous extract (CA)

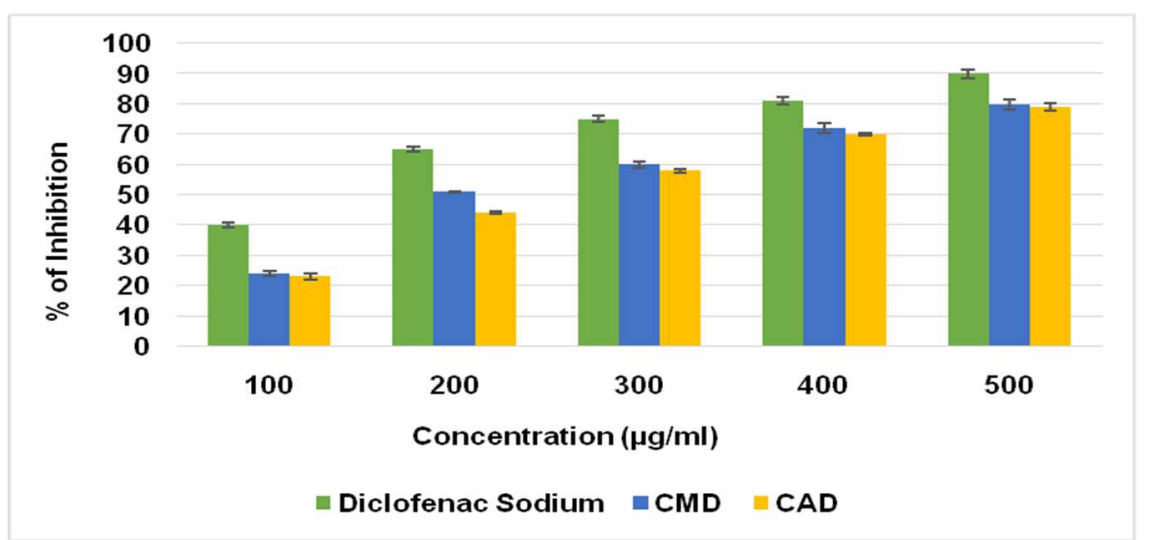

Fig. 12: Anti-inflammatory activity of dried coconut sprouts methanol extract (CMD) and aqueous extract (CAD)

The fresh coconut sprouts methanol extract have shown maximum anti-inflammatory activity than the dried sprouts. The results revealed that the fresh coconut sprouts have higher antiinflammatory potential and also have shown inhibition in a dosedependent manner. During protein denaturation, proteins lose their tertiary structure and secondary structure either by application of external stress or any compound, such as strong acid or base, a concentrated inorganic salt, an organic solvent or heat. Most biological proteins lose their biological function when denatured. Protein denaturation is one of the well-defined causes of inflammation [49]. Inflammation is reported to be the host response to trauma or as the defence mechanism against invasive organisms which eventually leads to redness, pain, swelling and temperature that evokes inflammatory cells (macrophages, neutrophils, monocytes, dendritic and mast cells) to invade the site of infection or wounds establishing an 'inflammatory micro-environment'. This leads to the death and degradation on the organism, agent or affected cells and eventual restoration of cellular or organ repair process [50]. Excessive activation of phagocytes, production of $\mathrm{O}_{2}$, $\mathrm{OH}$ radicals as well as non-free radicals $\left(\mathrm{H}_{2} \mathrm{O}_{2}\right)$ is seen in many inflammatory disorders which can be harmful to the tissues either by powerful direct oxidizing action by activating matrix metalloproteinase damage seen in various arthritis diseases [51,52]. Inflammation has become the focus of global scientific research since the current use of synthetic anti-inflammatory drugs leads to several adverse reactions. The results obtained are the clear evidence for consumption of the sprouts which may induce antiinflammation by being a strong natural anti-inflammatory agent.

Hence the coconut sprouts may be recommended to be used as a potent natural anti-inflammatory agent due to the presence of potential phytoconstituents such as terpenoids and flavonoids.

\section{Determination of antioxidant activity}

The antioxidant assay was carried out at different concentrations $(100,200,300,400,500 \mu \mathrm{g})$ of methanol and aqueous extracts of fresh and dried sprouts. Results revealed inhibition in a dosedependent manner. The antioxidant potential of the different sprout samples are determined based on their $\mathrm{IC}_{50}$ value. The $\mathrm{IC}_{50}$ value is the measure of the extract concentration that is required for $50 \%$ 
inhibition. LesserIC 50 value denotes the higher antioxidant potential of the sprouts.

\section{Hydrogen peroxide scavenging assay}

The fresh coconut sprouts methanol extract (CM) and aqueous extract (CA) showed per cent maximum inhibition of $85 \pm 1.2$ and $80 \pm 1.4$ respectively at a $500 \mu \mathrm{g}$ concentration with $\mathrm{IC}_{50}$ value of $231 \mu \mathrm{g} / \mathrm{ml}$ and $255.5 \mu \mathrm{g} / \mathrm{ml}$ (fig. 13). The dried coconut sprouts methanol extract (CMD) and aqueous extract (CAD) showed per cent maximum inhibition of $83 \pm 1.1$ and $78 \pm 1.2$ respectively at $500 \mu \mathrm{g}$ concentration with $\mathrm{IC}_{50}$ value of $238.1 \mu \mathrm{g} / \mathrm{ml}$ and $270.3 \mu \mathrm{g} / \mathrm{ml}$ (fig. 14). The hydrogen peroxide scavenging activity of standard ascorbic acid showed maximum percent inhibition of $90 \pm 1.5 \%$ at $500 \mu \mathrm{g}$ concentration with $\mathrm{IC}_{50}$ value of $149.1 \mu \mathrm{g} / \mathrm{ml}$.

$\mathrm{H}_{2} \mathrm{O}_{2}$ is a weak oxidising agent and can also inactivate few enzymes directly, usually through oxidation of essential thiol (-SH) groups. $\mathrm{H}_{2} \mathrm{O}_{2}$ react with $\mathrm{Fe}^{2+}$ and possibly $\mathrm{Cu}^{2+}$ ions resulting in the formation of hydroxyl radical which may be the origin of many of its toxic effects [53]. The results clearly show that sprouts have a good antioxidant potential. Thus the results are with clear evidence having prominent antioxidant potential irrespective of the sprouts fresh and dried form using different solvents.

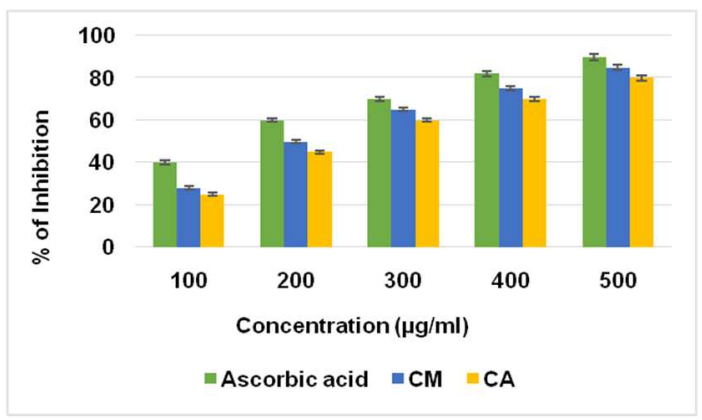

Fig. 13: Hydrogen peroxide scavenging activity of fresh coconut sprouts methanol extract (CM) and aqueous extract (CA)

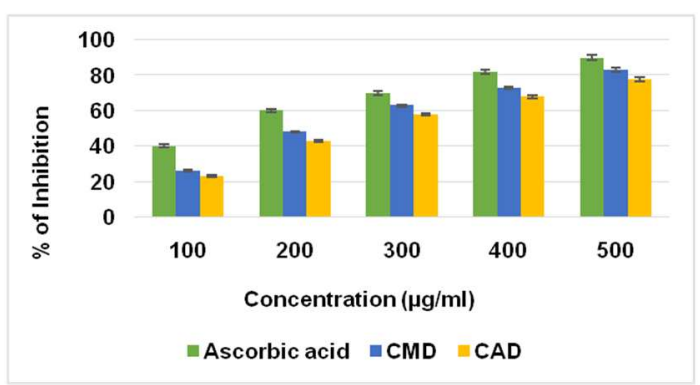

Fig. 14: Hydrogen peroxide scavenging activity of dried coconut sprouts methanol extract (CMD) and aqueous extract (CAD)

\section{Reducing power assay}

The fresh coconut sprouts methanol extract (CM) and aqueous extract (CA) showed IC 50 value of $196 \mu \mathrm{g} / \mathrm{ml}$ and $214.2 \mu \mathrm{g} / \mathrm{ml}$ (fig. 15). The dried coconut sprouts methanol extract (CMD) and aqueous

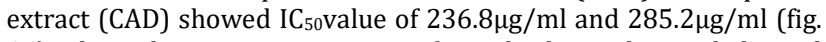
$16)$. The reducing power activity of standard ascorbic acid showed IC 50 value of $149.1 \mu \mathrm{g} / \mathrm{ml}$.

The reducing capacity of a compound may serve as a significant indicator of its antioxidant potential. The reducing ability was measured in terms of $\mathrm{Fe}^{3+}$ to $\mathrm{Fe}^{2+}$ transformation in the presence of different concentrations of the extract. Reducing power assay revealed that assayed sprouts were able to reduce the ferric ions $\left(\mathrm{Fe}^{3+}\right)$ to ferrous ions $\left(\mathrm{Fe}^{2+}\right)$ in a concentration-dependent manner [54].

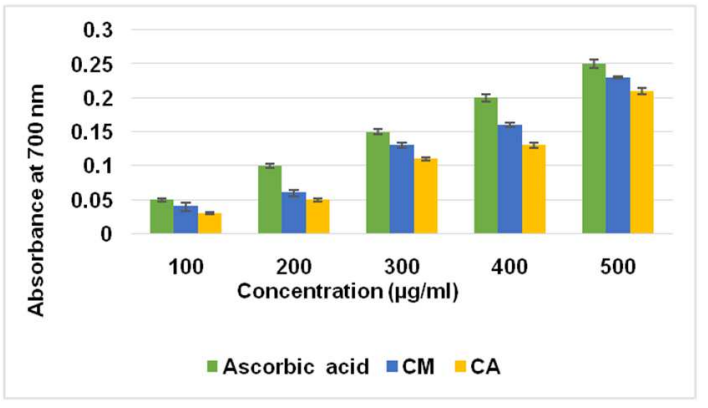

Fig. 15: Reducing power activity of fresh coconut sprouts methanol extract (CM) and aqueous extract (CA)

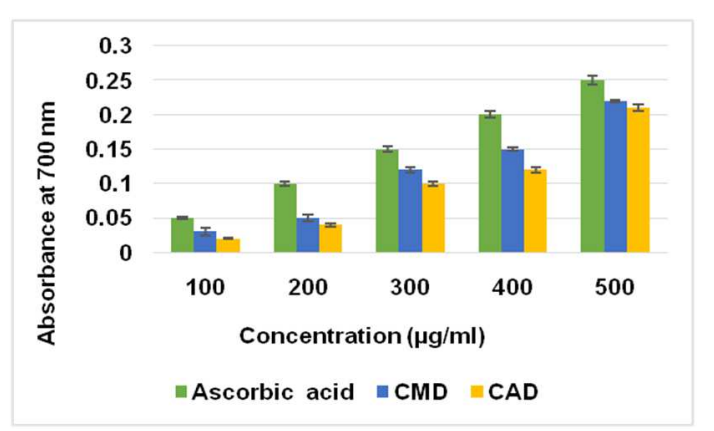

Fig. 16: Reducing power activity of dried coconut sprouts methanol extract (CMD) and aqueous extract (CAD)

\section{DPPH radical scavenging assay}

The fresh coconut sprouts methanol extract (CM) and aqueous extract (CA) showed per cent maximum inhibition of $88 \pm 1.2$ and $86 \pm 1.4$ respectively at $500 \mu \mathrm{g}$ concentration with $\mathrm{IC}_{50}$ value of $169.9 \mu \mathrm{g} / \mathrm{ml}$ and $184.2 \mu \mathrm{g} / \mathrm{ml}$ (fig. 17).

The dried coconut sprouts of the methanol extract (CMD) and the aqueous extract (CAD) showed per cent maximum inhibition of $84 \pm 1.2$ and $82 \pm 1.3$ respectively at $500 \mu \mathrm{g}$ concentration with $\mathrm{IC}_{50}$ value of $197.5 \mu \mathrm{g} / \mathrm{ml}$ and $205 \mu \mathrm{g} / \mathrm{ml}$ (fig. 18). The DPPH scavenging activity of standard ascorbic acid showed per cent maximum inhibition of $90 \pm 1.5$ at $500 \mu \mathrm{g}$ concentration with IC 50 value of $149.1 \mu \mathrm{g} / \mathrm{ml}$.

The electron donation ability of natural products can be measured by 2, 2-diphenyl-1-picrylhydrazyl (DPPH) purplecolored solution bleaching where the method is based on scavenging of DPPH through the addition of a radical antioxidant that decolourises the DPPH solution. The degree of color change is proportional to the concentration and potency of the antioxidants [55].

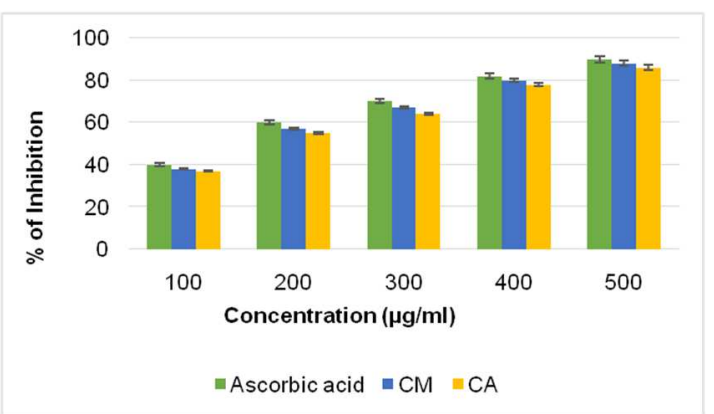

Fig. 17: DPPH free radical scavenging activity of fresh coconut sprouts methanol extract (CM) and aqueous extract (CA) 


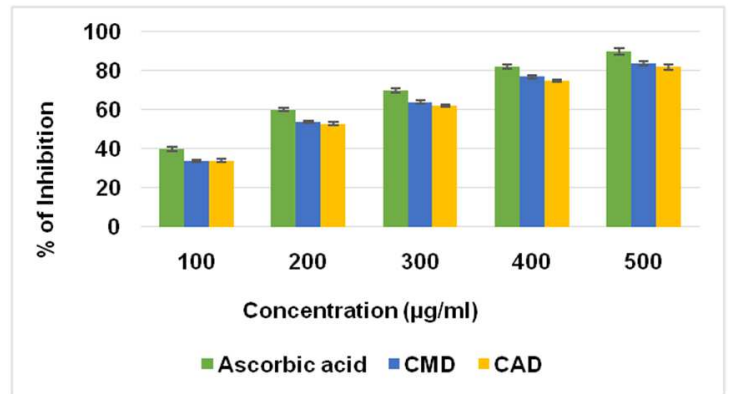

Fig. 18: DPPH free radical scavenging activity of dried coconut sprouts methanol extract (CMD) and aqueous extract (CAD)

Highly reactive free radicals like oxygen-derived radicals, which are mainly formed by exogenous chemicals or through endogenous metabolic processes in the human body. These are capable of oxidizing several cellular biomolecules like nucleic acids, enzymes, proteins, lipids and carbohydrates, consequently affecting the immune functions resulting in cell death and tissue damage [56]. Oxidative damage has a significant pathological role in several human diseases like cancer, atherosclerosis and arthritis [57]. The majority of the organisms are protected against free radical damage using enzymes like superoxide dismutase and catalase or bioactive compounds such as tocopherol, ascorbic acid and glutathione [58]. Several problems such as ageing, deterioration of physiological functions resulting in severe diseases followed by accelerated ageing are produced when the mechanism of antioxidant protection becomes unbalanced. Synthetic antioxidants used might be effective, but their safety and toxicity have been major concerns [59]. Much attention has been focused on the use of natural antioxidants to protect the human body from the oxidative damage by free radicals. Dietary antioxidants (natural food antioxidants) protect against free radicals such as reactive oxygen species in the human body.

Among the three antioxidant assays carried out in fresh and dried sprouts, DPPH assay revealed a potent antioxidant activity when compared to hydrogen peroxide scavenging assay and reducing power assay. Thus it clearly shows that the coconut sprouts are the potent natural antioxidant agents due to the presence of rich phytoconstituents namely terpenoids and flavonoids.

Terpenes have a significant role as signal compounds and growth regulators (phytohormones). These are the main constituents of essential oils and also sprouts having wound healing and antioxidant properties [60]. Most investigations regarding their role in human health reported their chemotherapeutic and antioxidant properties [61]. An important mode of action of terpenoids as antioxidants is to support other antioxidants like $\alpha$-tocopherol, thereby terpenoids not only being a strong antioxidant but also aid in the functioning of other antioxidants by showing synergistic effects.

Flavonoids are a large class of compounds, found in plants usually occurring as glycosides. These contain several polyphenols or phenol hydroxyl functions attached to ring structures. The cleavage of the glycosidic ring takes place in the gastrointestinal tract thereby releasing the free polyphenols. The chemical activities of polyphenolic components in terms of their reducing properties as hydrogen or electron donating agents predict their potential for action as free radical scavengers (antioxidants). The free radical scavenging activities of the sprout extracts may be attributed to the presence of flavonoids in the extracts [62]

DPPH radical scavenging activity of the studied sprouts was compared with the standard ascorbic acid. The fresh and dried methanolic and aqueous extracts of coconut sprouts revealed a prominent free radical scavenging activity on par with the standard ascorbic acid used. Thus, the consumption of the sprouts can be beneficial in preventing oxidative stress-related degenerative diseases.

\section{Thin layer chromatography (TLC) analysis}

The methanol extract of the fresh sprout sample showed good results for antibacterial and antioxidant assays, hence TLC analysis was carried out in fresh sprouts samples of methanol extract. Methanol extract of fresh coconut sprouts (CM) using the solvent system n-butanol: pyridine: water (1:1:1), showed yellow colour with a Rf value of 0.71 indicating the presence of proteins, with the solvent system Chloroform: Methanol: Water (30:4:1), greenish colour with $\mathrm{Rf}$ value of 0.3 indicating the presence of terpenoids and using the solvent system, Chloroform: Methanol (96:4), yellowishorange colour with Rf value of 0.86 indicating the presence of flavonoids (fig. 19).

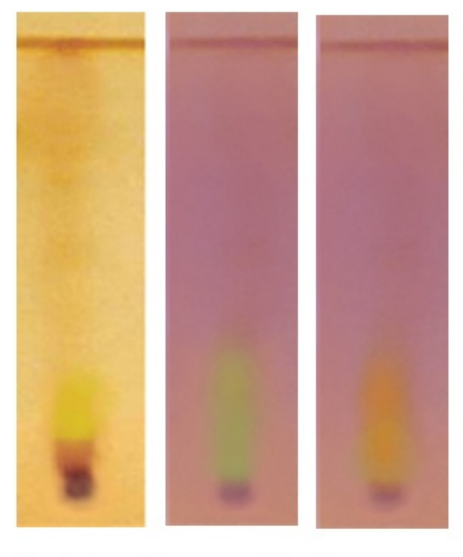

Proteins Terpenoids Flavonoids

Fig. 19: TLC Analysis for fresh coconut sprouts methanol extract (CM)

A human diet with several plant proteins includes a diverse range, which vary in terms of amino acid composition and its digestibility. These are capable of satisfying the human needs for all ages when consumed in appropriate mixtures. Recent data shows that intake of protein based diets reduces the risks of cardiovascular disease, hypertension and osteoporosis. The terpenoids show significant pharmacological activities, such as antiviral, antibacterial, antimalarial, anti-inflammatory, inhibition of cholesterol synthesis and anticancer activities [63]. Flavonoids are of great significance because of its antioxidant activity, activities of 5-lipoxygenase, cyclooxygenase, protein kinase $\mathrm{C}$, tyrosine kinase $\mathrm{C}$, genetic toxicity and they have free radical scavenging and antioxidation properties which are mainly responsible for several anticancer and anti-ageing activities [64]. Hence the results confirmed the presence of various bio-constituents such as proteins, terpenoids and flavonoids in the methanolic fresh coconut sprouted sample.

\section{Gas chromatography-mass spectrometry (GC-MS) analysis}

GC-MS is a combination of two different analytical techniques, Gas Chromatography (GC) and Mass Spectrometry (MS) used to analyze complex organic and biochemical mixtures [65]. Since the methanol extract of the fresh coconut sprout samples had a higher amount of phytoconstituents and showed prominent results for antibacterial, anti-inflammatory and antioxidant assays, the GC-MS analysis was carried out in fresh coconut sprout samples of methanolic extract to analyse the presence of specific bioactive compounds. The GC-MS spectrum of methanol extract of fresh coconut sprouts (CM), indicated the presence of various compounds like isosorbide dinitrate, $\mathrm{n}$-decanoic acid, pyrrolidine, 1,3-propanediol, D-glycero-Dido-heptose, xylitol, ethylene diacrylate, $n$-capric acid, ascorbic acid, n-nondecanol-1, 2-chloroethyl linoleate, cis-vaccenic acid, DL-Phenyl alanine, glycerol tri caprylate, caprylic anhydride, squalene, 4nitrophenyl caprylate (fig. 20 and table 3). The compounds are mostly of fatty acids, free amino acids, vitamins, terpenoids and other small functional groups. These compounds have the antimicrobial, anti-oxidant, anti-ulcer, anti-cancer properties. In recent decades, consumption of natural foods like sprouts has attracted huge attention, since many epidemiological and biochemical studies have consistently demonstrated clear and significant studies regarding regular intake of these natural food products which has reduced the rates of heart diseases, common 
cancers, ageing and other degenerative diseases. They are of great biological significance because of the presence of several antioxidants, especially antioxidative vitamins, including $\alpha$ tocopherol, ascorbic acid (vitamin C), and provitamin A. Sprouts being a part of regular diet in considerable amounts, they apparently provide long-term health profiting effects. Thus, the GC-MS studies are further taken for In silico work with the compounds identified for various biological activities, particularly with anti-inflammatory and antiulcer properties.

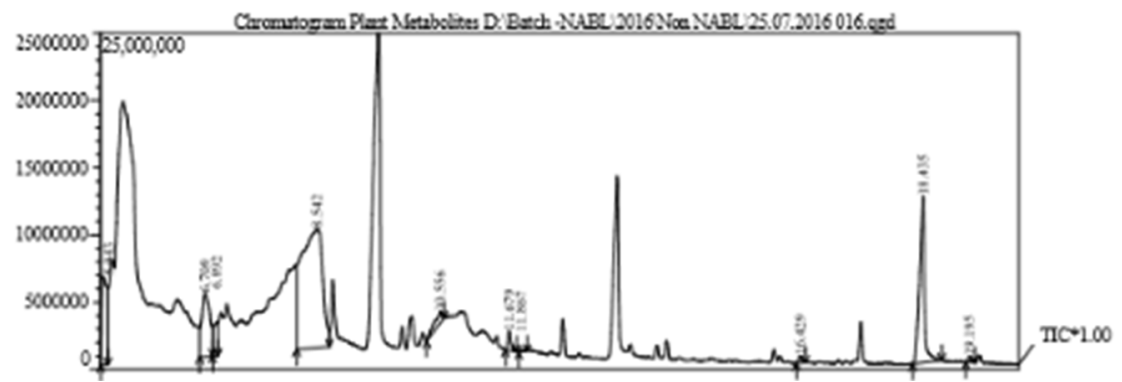

Fig. 20: GC-MS Spectrum of fresh coconut sprouts methanol extract (CM)

Table 3: GC-MS Analysis of fresh coconut sprouts methanol extract (CM)

\begin{tabular}{|c|c|c|c|c|c|c|}
\hline Peak & R. Time & Name & Area & Area \% & Height & Height \% \\
\hline 1 & 5.043 & Isosorbide Dinitrate & 39810397 & 8.23 & 6591365 & 11.79 \\
\hline 2 & 6.709 & n-Decanoic acid & 44381385 & 9.18 & 4734461 & 8.47 \\
\hline 3 & 6.892 & Pyrrolidine & 13113688 & 2.71 & 2449370 & 4.38 \\
\hline 4 & 8.542 & 1,3-Propanediol & 212138815 & 43.86 & 8878208 & 15.88 \\
\hline 5 & 10.556 & D-Glycero-D-ido-heptose & 8336666 & 1.72 & 789377 & 1.41 \\
\hline 6 & 11.679 & Xylitol & 5116587 & 1.06 & 1451395 & 2.60 \\
\hline 7 & 11.867 & Ethylene diacrylate & 693200 & 0.14 & 172193 & 0.31 \\
\hline 8 & 16.429 & n-Capric acid & 1982916 & 0.41 & 533074 & 0.95 \\
\hline 9 & 18.435 & Ascorbic acid & 70770128 & 14.63 & 12407401 & 22.20 \\
\hline 10 & 19.195 & n-Nonadecanol-1 & 1621170 & 0.34 & 410036 & 0.73 \\
\hline 11 & 22.987 & 2-Chloroethyl linoleate & 10944235 & 2.26 & 2040071 & 3.65 \\
\hline 12 & 23.179 & Cis-Vaccenic acid & 49223633 & 10.18 & 8484243 & 15.18 \\
\hline 13 & 23.417 & DL-Phenylalanine & 3273215 & 0.68 & 513496 & 0.92 \\
\hline 14 & 28.953 & Glycerol tricaprylate & 3125292 & 0.65 & 793461 & 1.42 \\
\hline 15 & 29.361 & Caprylic anhydride & 6800088 & 1.41 & 1574321 & 2.82 \\
\hline 16 & 43.652 & Squalene & 3877251 & 0.80 & 1517523 & 2.72 \\
\hline \multirow[t]{2}{*}{17} & 45.075 & 4-Nitrophenyl caprylate & 8486145 & 1.75 & 2550879 & 4.56 \\
\hline & & & 483694811 & 100.00 & 55890874 & 100.00 \\
\hline
\end{tabular}

\section{In silico analysis (Docking studies)}

GC-MS studies confirmed the presence of fatty acids, free amino acids, vitamins, terpenoids and other small functional groups. From the GC-MS analysis, screening was carried out for the compounds related to the anti-ulcer property.

Among the compounds screened, squalene from fresh coconut sprouts was found to be related to the present study having antiulcer activity. Squalene, a triterpenoid is an anti-ulcer, anticancer agent. It is also used as an immunologic adjuvant in vaccines. Diclofenac sodium was used as a standard.

Diclofenac is a non-steroidal anti-inflammatory agent (NSAID) with antip yretic and analgesic actions. It is primarily available as the sodium salt. The target protein of Helicobacter pylori, was obtained from Protein Data Bank (http://www.rcsb.org/pdb/)-PDB ID: 1G60. The bioactive compound details (squalene) was retrieved from Pubchem database. Mcule [https://mcule.com/] is an integrated drug discovery platform providing drug discovery tools, high-quality compound database and professional compound delivery. These components are integrated together and can be accessed via a clean and simple web interface. The bioactive compounds docked against the target protein in mcule database showed the anti-ulcer property of the compounds through docking scores. More negative values are an indication of higher binding affinity. Rigid docking method was followed where the bond angles, bond lengths were not modified at any stage of the analysis.

Docking analysis of squalene from fresh coconut sprouts methanol extract (CM) showed docking scores of-7.7,-7.6,-7.5 and-7.3 (fig. 21). Docking analysis of standard diclofenac sodium showed docking scores of-7.5,-7.3,-7.1 and-6.8 (fig. 22). Maximum binding affinity was noted for squalene against Helicobacter pylori than the standard drug compound diclofenac sodium.

Thus docking results are clear evidence for coconut sprouts having anti-ulcer properties. Thus the sprouts with enriched phytoconstituents can be recommended as a natural treatment for ulcer problems. The maximum binding affinity was reported with fresh methanolic extracts of coconut sprouts with a squalene-an antiulcer agent when compared with the standard diclofenac sodium. Specifically, coconut sprouts can be extensively used as an anti-ulcer agent as it is already existing as a traditional practice of consuming the coconut sprouts for various stomach disorders.

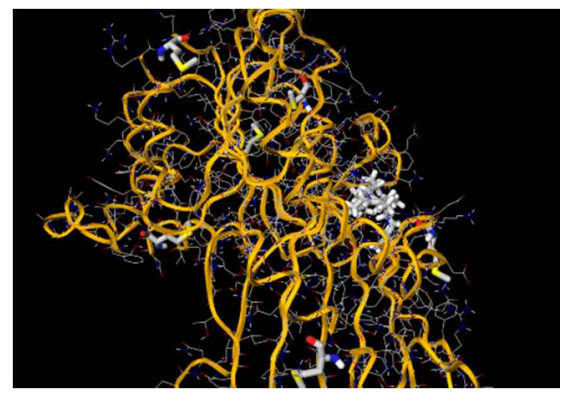

Fig. 21: Illustration of squalene compound from fresh coconut sprouts methanol extract (CM) Docked with Target Protein 1G60-Helicobacter pylori 


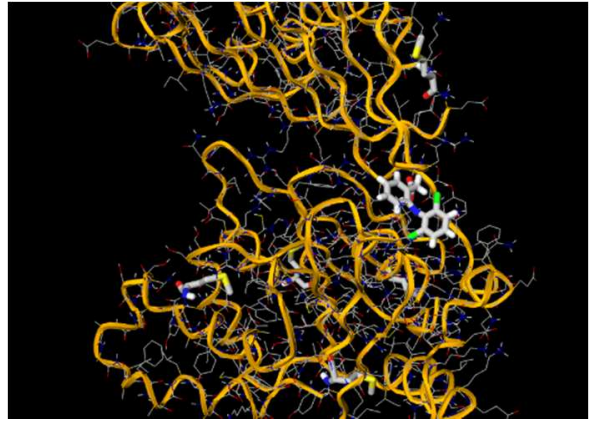

Fig. 22: Illustration of standard diclofenac sodium compound docked with target protein 1G60-Helicobacter pylori

\section{CONCLUSION}

The present study revealed that the fresh coconut sprouts are enriched with phytoconstituents such as proteins, carbohydrates, terpenoids and flavonoids which possess strong antibacterial, antiinflammatory and antioxidant activities. Further, GC-MS and docking studies confirmed the presence of squalene, a triterpenoid showing a strong specific antiulcer affinity against the target protein Helicobacter pylori, an ulcer causing bacteria.

Sprouts have been used in the diet as healthy food and in addition to being a good source of basic nutrients; they also have important phytoconstituents with disease preventive and health promoting properties. Moreover, sprouts are believed to have stronger defences and metabolic pathways than the parent seeds. In recent past, there is an increasing need for the consumption of nutrient rich diet from the natural sources. The fresh coconut sprouts are natural, economically potent food source for human health and can be a nutrient supplement with cost effective approach. The dried sprouts can also be recommended to the food industry for the large-scale production of nutrient-based foods with a quality check.

\section{ACKNOWLEDGEMENT}

The authors thank Mrs. Prema Sampathkumar, Associate Professor and Head, the Faculty members and non-teaching staff of Department of Plant Biology and Plant Biotechnology, Ethiraj College for Women (Autonomous), Chennai-600 008 and Dr. Mrs. A. Nirmala, Principal, Ethiraj College for women (Autonomous) for their valuable support, encouragement throughout the entire period of research. We would also like to express our sincere thanks for the facilities extended by the Central Instrumentation Centre of Ethiraj College for Women.

\section{CONFLICTS OF INTERESTS}

The authors declared that they had no conflicts of interests.

\section{REFERENCES}

1. AACR, Broccoli sprouts, cabbage, Ginkgo biloba and garlic: a grocery list for cancer prevention, Am Asso Cancer Research. Public and Media: News; 2005.

2. Schenker S. Facts behind the headlines, Broccoli, British Nutrition Foundation-Nutrition Bulletin; 2002;27:159-60.

3. Finley JW. Proposed criteria for assessing the efficacy of cancer reduction by plant foods enriched in carotenoids, glucosinolates, polyphenols and seleno-compounds. Ann Bot 2005;95:1075-96

4. Webb GP. Dietary supplements and functional foods, Blackwell Publishing Ltd., Oxford; 2006. p. 1-120.

5. Rufus Auxilia L, Rachel Regi Daniel, Shenbagarathai R. Phytochemical analysis of seed extracts Macrotyloma uniflorum (Horse gram). Int J Curr Res 2013;5:3339-42.

6. EFSA, Scientific Opinion on the risk posed by Shiga-toxinproducing Escherichia coli (STEC) and other pathogenic bacteria in seeds and sprouted seeds. European Food Safety Authority; 2011.
7. Lima EBC, CNS Sousa, LN Meneses, NC Ximenes, GS Vasconcelos, NBC Lima, et al. Cocos nucifera (L.) (Arecaceae): a phytochemical and pharmacological review. Braz J Med Biol Res 2015;48:953-64.

8. Anitha Madhusoodhanan Chikku, Thankappan Rajamohan. Dietary coconut sprout beneficially modulates cardiac damage induced by isoproterenol in rats. Bangladesh J Pharmacol 2012;7:258-65.

9. Bandyopadhyay D, Biswas K, Bhattacharyya M, Reiter RJ, Banerjee RK. Gastric toxicity and mucosal ulceration induced by oxygen-derived reactive species, protection by melatonin. Curr Mol Med 2001;1:501-13.

10. Ludovico B, Eric S, Van DV. Helicobacter pylori cytotoxinassociated gene A subverts the apoptosis-stimulating protein of p53 ASPP2 tumor suppressor pathway of the host. Proc Natl Acad Sci USA 2011;108:9238-43.

11. Martin JB. Not all Helicobacter pylori strains are created equal, should all be eliminated. Lancet 1997;349:1020-22.

12. Fan XG, Kelleher D, Fan XJ, Xia HX, Keeling PW. Helicobacter pylori increase proliferation of gastric epithelial cells. Gut 1996;38:19-22.

13. Akram M, Shahabuddin, Ahmed A, Usmanghani K, Hannan A, Mohiuddin E. Peptic ulcer and Helicobacter pylori eradication. Int J Med Sci 2010;2:370-5.

14. Leslie. Peptic ulcer: a reappraisal of its peptic aetiology. Ann R Coll Surg Engl 1972;50:145-63.

15. Nagar V, Bandekar JR. Microbiological quality of packaged sprouts from supermarkets in Mumbai, India. Int J Food Safety Nutr Public Health 2009;2:165-75.

16. Eloff JN. Which extractant should be used for the screening and isolation of antimicrobial components from plants? Ethnopharmacol 1998;60:1-8.

17. Sofowora AO. Medicinal plants and traditional medicine in Africa. 2nd ed. Sunshine house, Ibadan, Nigeria: Spectrum books Ltd., Screening plants for Bioactive agents; 1993. p. 134-56.

18. Harborne AJ. Phytochemical methods-a guide to modern techniques of plant Analysis, Thomas Science Publications; 1998.

19. Raaman N. Phytochemical Analysis, New India Publishing Agency; 2006. p. 19-24.

20. Trease GE, Evans WC. Pharmacognosy. 15th ed. London, Saunders publishers; 2002. p. 42-4.

21. Miller GL. Use of dinitro salicylic acid reagent for determination of reducing sugar. Anal Chem 1972;31:426-8.

22. Nelson N. A photometric adaptation of the Somogyi method for the determination of glucose. J Biol Chem 1944;153:375-80.

23. Lowry $\mathrm{OH}$, NJ Rosebrough, AL Fan, RJ Randall. Protein measurement with the Folin-phenol reagent. J Biol Chem 1951;193:265-75.

24. Patel S, Patel J, Patel RK. To study proximate analysis and biological evaluation of Triphala Guggulu formulation. Int J PharmTech Res 2012;4:1520-6.

25. Pallab K, Tapan B, Tapas P, Ramen K. Estimation of total flavonoids content (TPC) and antioxidant activities of methanolic whole plant extract of Biophytum sensitivum Linn. J Drug Delivery Ther 2013;3:33-7.

26. Ferguson N. A Textbook of Pharmacognosy, Max Millam Company; 1956. p. 191.

27. Wheeler EL, RE Ferrel. A method for phytic acid determination in wheat and wheat fractions. Cereal Chem 1971;48:312-20.

28. Mizushima Y, Kobayashi M. Interaction of anti-inflammatory drugs with serum proteins, especially with some biologically active proteins. J Pharma Pharmacol 1968;20:169-73.

29. Sakat S, Juvekar AR, Gambhire MN. In vitro antioxidant and anti-inflammatory activity of methanol extract of Oxalis corniculata Linn. Int J Pharm Pharm Sci 2010;2:146-55.

30. Ruch RT, Cheng SJ, Klaunig JE. Spin trapping of superoxide and hydroxyl radicals. Methods Enzymol 1984;105:198-209.

31. Oyaizu M. Studies on the product of browning reaction prepared from glucose amine. Jap J Nutr 1986;44:307-15.

32. Mansoor Ahmad, Farah Saeed, Mehjabeen, Noor Jahan. Evaluation of the insecticidal and antioxidant activity of selected medicinal plants. J Pharmacogn Phytochem 2013;2:153-8. 
33. Patel Rajesh M, Patel Natvar J. In vitro antioxidant activity of coumarin compounds by DPPH, superoxide and nitric oxide free radical scavenging methods. J Adv Pharm Edu Res 2011;1:52-68.

34. Achola KJ, RW Munenge. Bronchodilating and uterine activities of Ageratum conyzoides extract". Pharm Biol 1998;36:93-6.

35. Mamta Arora, Satnam Singh, Ramandeep Kaur. Phytochemical analysis, protein content and antimicrobial activities of selected samples of Glycine Max Linn. Int J Res Eng Technol 2013;2:570-4

36. Aun Syed, Nighat Fatima. In silico analysis and molecular docking studies of potential angiotensin converting enzyme inhibitor using quercetin glycosides. Pharmacognosy Mag 2015;11(Suppl 1):S123-S126.

37. Elena Penas, Rosario Gomeza, Juana Frias, Vidal-Valverde. Application of high-pressure treatment on Alfalfa (Medicago sativa) and Mung bean (Vigna radiata) seeds to enhance the microbiological safety of their sprouts. Food Control 2008;19:698-705.

38. McGarvey DJ, Croteau R. Terpenoid metabolism. Plant Cell 1995; 7:1015-26.

39. Indumathi, Durgadevi, Nithyavani, Gayathri. Estimation of terpenoid content and its antimicrobial property in Enicostemma litorrale. Int J ChemTech Res Coden (USA) 2014;6:4264-7.

40. Ravi Kumar P, G Shalini, M Jeyam. Phytochemical analysis and antioxidant activity of wheat grains and seedlings. J Pharm Sci Innov 2014;3:319-23.

41. Caterina Brajdes, Camelia Vizireanu. Sprouted buckwheat an important vegetable source of antioxidants. Food Technol 2012;36:53-60.

42. Ashima Bali, Satyanarayana T. Advances in microbial biotechnology, APH Publishing Corporation, New Delhi, India; 2009. p. 94-8.

43. Reddy NR. Occurrence, distribution, content, and dietary intake of phytate. In: Reddy NR, Sathe SK. Eds. Food Phytates. CRC Press; Boca Raton Florida: 2002. p. 25-51.

44. Skoog A, EJ Holler, SR Crouch. Principles of instrumental analysis. 6th ed. 2007. p. 1039.

45. Blakeslee K, Penner KP. Microorganisms and food-borne illness, Kansas State University Publication; 2006.

46. Stermitz FR, Tawara-Matsuda J, Lorenz P, Mueller P, Zenewicz L, Lewis. K, 5'-methoxyhydnocarpin-D and pheophorbide A: berberis species components that potentiate berberine growth inhibition of resistant Staphylococcus aureus. J Nat Prod 2000;63:1146-9.

47. Randhir R, Shetty K. Mung bean processed by solid-state bioconversion improves phenolic content and functionality relevant for diabetes and ulcer management. Innov Food Sci Emerg Technol 2007;8:197-204.

48. Smid EJ, Gorris LGM. Natural antimicrobials for food preservation. In: Rahman MS. Ed. Handbook of Food Preservation. Marcel Dekker, New York; 1999. p. 285-308.

49. Leelaprakash G, Mohan Dass S. In the vitro anti-inflammatory activity of methanol extract of Enicostemma axillare. Int J Drug Dev Res 2011;3:185-96.
50. Mitchell RN, Cotran RS. Acute and chronic inflammation. In: Robbins Basic Pathology Saunders, Philadelphia, USA; 2003;7:33-59.

51. Lewis. Anti-inflammatory drugs from plants and marine sources. Agents Actions Suppl 1989;27:3-373.

52. Cotran RS, Kumar V, Robbins SL. Pathologic basis of disease, Saunders WB company, Phildelphia, USA; 1994.

53. Antony De Paula Barbosa. An overview on the biological and pharmacological activities of saponins. Int J Pharm Pharma Sci 2014;6:0975-1491.

54. Suprava Sahoo, Goutam Ghosh, Debajyoti Das, Sanghamitra Nayak. Phytochemical investigation and in vitro antioxidant of an indigenous medicinal plant Alpinia nigra B. L. Burtt. Asian Pac J Trop Biomed 2013;3:871-6.

55. Saeed N, RK Muhammad, S Maria. Antioxidant activity, total phenolic and flavonoid contents of the whole plant extract Torilis leptophylla L. BMC Complementary Altern Med 2012;12:1-12.

56. Nilsson J, Stegmark R, Akesson B. Total antioxidant capacity in different pea (Pisum sativum) varieties after blanching and freezing, Food Chem 2004;86:501-7.

57. Halliwell B. Gutteridge, Oxygen toxicity, oxygen radicals, transition metals and diseases. Biochem J 1984;219:1-4.

58. Niki E, Shimaski H, Mino H. Antioxidantism-free radical and biological defense, Gakkai Syuppan Center, Tokyo; 1994. p. 3-16.

59. Imaida K, Fukushima S, Shivai T, Ohtani M, Nakanishi K, Ito N. Promoting activities of butylated hydroxyl anisole and butylated hydroxyl toluene on 2-stage urinary bladder caricinogensis and inhibition of $\gamma$-glutamyl transpeptidasepositive foci development in the liver of rats. 1983;4:885-9.

60. Singsaas EL, Lerdau M, Winter K, Sharkey TD. Isoprene increases thermotolerance of isoprene-emitting species. Plant Physiol 1997;115:1413-20.

61. Crowell PL. Terpenes in breast cancer prevention. Breast Cancer 1997;46:191-7.

62. Banani Dass, Manabendra Dutta Choudhury, Amitabha Dey, Anupam Das Talukdar, KH Nongallemia, Lokesh Deb. Antioxidant and anti-inflammatory activity of aqueous and methanolic extracts of rhizome part of drynaria quercifolia (L.) J. smith. Int J Pharm Pharm Sci 2014;6:43-9.

63. Nassar Z, Aisha A, Abdul Majid A. The pharmacological properties of terpenoids from Sandoricum Koetjape, webmed central; 2010. p. 2-11.

64. Sharma DK. Pharmacological properties of flavonoids including flavonolignans-Integration of petro crops with drug development in plants. J Sci Indus Res 2006;65:477-84.

65. Syed Zameer Hussain, Khushnuma Maqbool. GC-MS: principle, technique and its application in food science. Int J Curr Sci 2014;13:116-26.

\section{How to cite this article}

- Abiraami Valli S, S Uma Gowrie. A study on the bioactive potential of fresh and dried sprouts of cocos nucifera L.-an in vitro and in silico approach. Int J Pharm Pharm Sci 2017;9(3):129-142. 